\title{
DETERMINANTES ESPACIAIS DAS INTERNAÇÕES HOSPITALARES DO SISTEMA ÚNICO DE SAÚDE POR CÂNCER DE MAMA NAS MICRORREGIÕES DO BRASIL
}

\author{
Olívia Takahashi Margarido * \\ Cássia Kely Favoretto Costa ${ }^{\dagger}$ \\ José Luiz Parré ‡
}

\begin{abstract}
Resumo
O objetivo deste artigo foi analisar os determinantes econômico e de gestão de saúde das internações hospitalares do Sistema Único de Saúde por câncer de mama feminino entre as microrregiões do Brasil no ano de 2013. Para tanto, utilizou-se a Análise Exploratória de Dados Espaciais (AEDE), além da especificação de modelos econométricos espaciais e do modelo GWR (Geographically Weighted Regression). Observou-se associação positiva de PIB per capita, mamógrafos e consultas da Atenção Básica e negativa das equipes de saúde sobre as internações hospitalares pela doença, com destaque para a influência das regiões vizinhas e do impacto local.
\end{abstract}

Palavras-chave: câncer de mama, econometria espacial, economia da saúde.

\begin{abstract}
The aim of this article was to analyze the economic and health management determinants of hospital admissions of the Brazilian public health system (SUS) by female breast cancer among the micro-regions of Brazil in 2013. Therefore, the Exploratory Spatial Data Analysis and the specification of spatial econometric models and the GWR (Geographically Weighted Regression) model were used. Positive association of GDP per capita, mammography and primary care consultations, and negative association of health professionals on hospital admissions for breast cancer were observed, with the influence of neighboring regions and local impact.
\end{abstract}

Keywords: breast cancer, spatial econometrics, health economics.

JEL classification: C31, C50, I10, R10.

DOI: http : / dx.doi .org/10.11606/1980-5330/ea146620

\footnotetext{
* Mestre em Economia pelo Programa de Pós-Graduação em Ciências Econômicas da Universidade Estadual de Maringá (UEM). E-mail: olivia_margarido@hotmail.com

${ }^{\dagger}$ Docente no Programa de Pós-Graduação em Ciências Econômicas e no Departamento de Economia da Universidade Estadual de Maringá (UEM). E-mail: ckfcosta@uem.br

‡ Docente no Programa de Pós-Graduação em Ciências Econômicas e no Departamento de Economia da Universidade Estadual de Maringá (UEM).E-mail: jlparre@uem.br
} 


\section{Introdução}

O câncer de mama é a segunda neoplasia mais comum entre as mulheres em nível mundial e nacional, depois do câncer de pele não melanoma (Santos et al. 2013, Guerra et al. 2015, Brasil 2017a). É uma doença crônica que apresenta altas taxas de incidência, internações hospitalares e mortalidade, sendo classificada como um problema de saúde pública (Brasil 2013, Mohaghegh et al. 2015, Rodrigues et al. 2015, Xia et al. 2016).

No período recente, a incidência do câncer de mama no Brasil apresentou tendência crescente. O risco estimado desta doença passou de 52 casos a cada 100 mil mulheres em 2012 para 56,20 casos a cada 100 mil em 2016. Em termos regionais, as áreas mais desenvolvidas economicamente registraram as maiores chances estimadas deste agravo no mesmo período, com destaque para o Sul (a incidência passou de 65 casos/100 mil para 74,30 casos/100 mil, respectivamente) do país (Brasil 2011, 2015).

O risco de desenvolvimento do câncer de mama pode estar associado ao processo de urbanização da sociedade, dado que essa doença é mais comum em mulheres que residem em cidades (Alvarez et al. 2009, Brasil 2010a, Dey et al. 2010, Chien et al. 2012, Fei et al. 2015, Zhou et al. 2015, Madhu et al. 2016), bem como naquelas com elevado status socioeconômico (Alvarez et al. 2009, Brasil 2010a, Cunningham et al. 2010, Larsen et al. 2011, Chien et al. 2012, Palmer et al. 2012, Fei et al. 2015, Goldberg et al. 2015, Mohaghegh et al. 2015, Zhou et al. 2015).

A relação entre o maior status socioeconômico da mulher e a incidência de câncer de mama pode ser explicada, por um lado, por alguns fatores, tais como: primeiro filho em idade mais avançada (Palmer et al. 2012, Fei et al. 2015, Goldberg et al. 2015), não ter filhos (Alvarez et al. 2009, Cunningham et al. 2010, Larsen et al. 2011) ou ter um menor número de filhos devido à busca por uma melhor qualificação profissional, inserção das mulheres no mercado de trabalho (Mohaghegh et al. 2015), histórico de abortos, tempo mais curto de amamentação (Cunningham et al. 2010, Mohaghegh et al. 2015), uso prolongado de contraceptivos orais (Palmer et al. 2012, Fei et al. 2015), maior uso de terapia de reposição hormonal (Alvarez et al. 2009, Cunningham et al. 2010, Larsen et al. 2011, Fei et al. 2015), obesidade (Alvarez et al. 2009, Cunningham et al. 2010, Larsen et al. 2011, Fei et al. 2015), inatividade física (Zhou et al. 2015), consumo de álcool (Alvarez et al. 2009, Cunningham et al. 2010, Larsen et al. 2011, Fei et al. 2015), dieta alimentar inadequada, entre outros (Alvarez et al. 2009, Fei et al. 2015, Zhou et al. 2015).

Por outro lado, a associação entre maior condição socioeconômica da mulher e o elevado número de casos de câncer de mama pode ser resultado do melhor acesso aos serviços de saúde e a detecção precoce da doença (Alvarez et al. 2009, Cunningham et al. 2010, Chien et al. 2012, Fei et al. 2015). As pessoas do sexo feminino com renda mais alta, tendem a realizar mais exames, o que pode contribuir na identificação desta neoplasia (Lima-Costa \& Matos 2007, Goldberg et al. 2015, Guerra et al. 2015, Rodrigues et al. 2015, Zhou et al. 2015).

A detecção em estágios iniciais da neoplasia mamária (lesões menores que dois centímetros de diâmetro) está associada a um prognóstico mais favorável. Este prognóstico é realizado por meio do autoexame das mamas, ultrassom e mamografia. Além disso, abrange o rastreamento da doença, que é feito somente pela mamografia, por ser o único exame capaz de identificar lesões 
não palpáveis. Destaca-se que a detecção precoce no Brasil ocorre na Atenção Primária do Sistema Único de Saúde - SUS, a partir da atuação das equipes do Programa Saúde da Família (Santiago 2012, Brasil 2013, Teixeira et al. 2017).

A prevenção ao câncer de mama é tida como fundamental para reduzir o número de casos dessa doença, bem como os custos econômicos e sociais gerados por ela ao sistema de saúde (World Health Organization 2014, Brasil 2015). Custos diretos (envolvendo consultas médicas, internações hospitalares, medicamentos, dispositivos médicos e cuidados de longa duração) e indiretos (como transporte, alojamento para tratamentos a longa distância, desemprego, perda de produtividade, entre outros) podem ser minimizados com ações efetivas de detecção precoce e redução das desigualdades no acesso, diagnóstico e tratamento desta enfermidade (National Institutes of Health 2007, Kendall 2010, Boland \& Murphy 2012, Brasil 2013, World Health Organization 2014).

No Brasil, ao se considerar a oferta e a demanda por serviços de saúde, pode-se evidenciar acentuadas diferenças na distribuição de profissionais de saúde e no acesso a ações de detecção precoce do câncer de mama (Brasil 2007, Silveira \& Pinheiro 2014, Guerra et al. 2015, Scheffer 2015, Domingos et al. 2017). Na área de Economia da Saúde, o efeito regionalizado de um sistema de saúde vem sendo avaliado por meio dos modelos econométricos de análise espacial (Goovaerts 2006, Müller 2009, Bello 2010, Perinetti 2015, Zhou et al. 2015). Esta metodologia empírica permite uma melhor visualização da dinâmica de distribuição espacial de doenças e agravos, bem como da demanda e acesso aos serviços de saúde. Além disso, por meio dessa técnica é possível compreender os determinantes socioeconômicos, demográficos e de gestão desse sistema que determinam as condições de vida e o estado de saúde das mulheres, de modo que medidas de intervenção possam ser propostas de acordo com a necessidade de cada microrregião do país (Brasil 2007, Madhu et al. 2016).

Destaca-se que, no Brasil, o SUS é um dos principais financiadores dos tratamentos do câncer de mama, incluindo exames, medicamentos e terapias especializadas a toda população. Estima-se que o SUS seja responsável por $75 \%$ dos atendimentos em quimioterapia, radioterapia, hemodiálise e hemoterapia, incluindo aqueles realizados na rede privada de saúde conveniada (Brasil 2010b, 2017a). Cabe destacar que, além dessa significativa participação, as informações acerca dessa doença (por exemplo, de incidência, internações, mortalidade, entre outras) para cada munícipio e estado do país são disponibilizadas de forma gratuita pelo Ministério da Saúde, o que contribui para o desenvolvimento de pesquisas científicas, indicadores regionais e avaliação de políticas públicas.

Neste sentido, a relevância da presente pesquisa para o desenho do SUS e para o combate ao câncer de mama no Brasil ocorre sob dois aspectos. O primeiro está relacionado à identificação dos determinantes econômico e de gestão das internações hospitalares do SUS por essa doença em cada microrregião brasileira. O segundo está ligado à inovação metodológica utilizada para captar o efeito regionalizado da estrutura do setor saúde no país. A partir disso, espera-se que políticas de saúde pública sejam mais bem direcionadas para cada área específica, por meio da adequada distribuição de recursos físicos (mamógrafos), humanos (profissionais de saúde) e a realização de ações mais eficazes de prevenção e promoção à saúde das mulheres. É importante frisar que, uma vez que o governo e a sociedade reconheçam que esta neopla- 
sia representa um grande ônus socioeconômico, ainda existem lacunas para melhor compreensão das implicações deste problema.

Diante do exposto, o objetivo deste artigo é analisar os determinantes econômico (PIB per capita) e de gestão em saúde (mamógrafos, equipes de saúde e consultas da Atenção Básica) das internações hospitalares do SUS por câncer de mama feminino entre as microrregiões do Brasil no ano de 2013. Para tanto, utiliza-se a Análise Exploratória de Dados Espaciais (AEDE), os modelos econométricos espaciais e o modelo GWR (Geographically Weighted Regression).

O artigo está dividido em mais quatro seções, além desta introdução e das considerações finais. A segunda seção apresenta a revisão de literatura, que trata de trabalhos empíricos que aplicaram a técnica de análise espacial para o câncer de mama. A terceira seção abrange a caracterização dos fatores de gestão em saúde relacionados a esta neoplasia. A quarta seção aborda a descrição e fonte de dados, bem como o método empírico. A quinta seção corresponde a análise e discussão dos resultados.

\section{Revisão de Literatura}

A distribuição geográfica do câncer de mama em nível mundial e nacional vem sendo objeto de estudo de pesquisadores na área da saúde e, de forma mais recente, em Economia da Saúde. Em geral, as pesquisas utilizam as informações de incidência e mortalidade por esse tipo de doença para analisar a forma em que se distribuem no espaço. Contudo, cabe destacar que não foram encontrados (até o momento) trabalhos que usaram a variável internações hospitalares do SUS por essa doença, como realizado na presente pesquisa. Assim, a revisão de literatura foi feita considerando estudos de incidência e mortalidade por esta enfermidade. Como uma contribuição deste artigo, foi elaborada a Tabela 1 sistematizando a revisão de literatura sobre o tema.

Inicialmente são consideradas pesquisas que utilizaram somente o mapeamento geográfico para analisar a distribuição da incidência e mortalidade por câncer de mama, destacando-se em termos internacionais: Fukuda et al. (2005), Vieira et al. (2008), Alvarez et al. (2009), Chien et al. (2012), Beysebayev et al. (2015), Herrmann et al. (2015), Madhu et al. (2016), Ocaña-Riola et al. (2016), Ocaña-Riola et al. (2016) e Xia et al. (2016). Já em nível nacional, tem-se: Wünsch Filho \& Moncau (2002), Santos et al. (2009) e Zapponi \& Melo (2010).

Posteriormente, a presente revisão enfoca estudos que usaram como instrumento metodológico a Análise Exploratória dos Dados Espaciais (AEDE). No âmbito internacional, tem-se os trabalhos de Goovaerts (2006), Perinetti (2015) e Zhou et al. (2015), e nacionalmente, Müller (2009) e Bello (2010).

Fukuda et al. (2005) buscaram identificar possíveis aglomerações espaciais de altas taxas de mortalidade por câncer feminino em dados municipais do Japão entre 1993 e 1998. As aglomerações da mortalidade por essa doença ocorreram em municípios urbanos, com mulheres que possuíam nível de renda e educação mais altos, ligados a fatores como hábitos alimentares inadequados e baixo número de filhos. Concluíram que os agrupamentos observados, por meio de mapas, ocorreram em localidades com características socioeconômicas homogêneas (áreas urbanas, com maior status socioeconômico), implicando a necessidade de estratégias de saúde pública específicas para aquelas áreas. 
Por sua vez, Vieira et al. (2008) analisaram o alto número de casos do câncer de mama em Cape Cod, Massachusetts (EUA), por meio de mapas de distribuição geográfica. Associaram a história dos participantes no período de 1947 a 1993 e o risco de diagnóstico da doença entre 1983 e 1993, encontrando forte associação entre residir perto da Reserva Militar de Massachusetts entre 1947 e 1956 e o risco de diagnóstico de câncer de mama entre 1983 e 1993 . Os resultados sugerem que análises futuras devem ser conduzidas para explorar os motivos dessa associação geográfica, mas já apontando causas ambientais (ingestão de água contaminada e poluição do ar perto da reserva militar) como possíveis determinantes da doença.

Alvarez et al. (2009) utilizaram dados de 1999 a 2003 para descrever a distribuição geográfica da incidência de câncer de mama e de colo de útero em Cuba. De forma específica para a neoplasia mamária, com o auxílio de mapas, evidenciaram alto risco de incidência dessa doença nos municípios da Província de Havana (nível de urbanização de 100\%), com população predominantemente branca (historicamente relacionado ao status socioeconômico), número pequeno de filhos e idade avançada na primeira gravidez. Conclúíram que a distribuição espacial da incidência do câncer de mama e de colo de útero reflete as diferenças no estilo de vida (comportamento reprodutivo, como nuliparidade, número pequeno de filhos, idade avançada na primeira gravidez, menopausa tardia e dieta alimentar inadequada) e no status socioeconômico entre as diferentes regiões do país destacado.

Chien et al. (2012) analisaram tanto a incidência em estágio inicial e avançado quanto a mortalidade por câncer de mama no período de 1988 a 2008, por meio de dados públicos dos Estados Unidos. Evidenciaram associação positiva entre a disponibilidade de profissionais de saúde (definido como o número de médicos de cuidado primário por 100 mil mulheres na faixa etária de 40 anos ou mais) e os indicadores do câncer de mama (incidência e mortalidade). Por sua vez, relação negativa entre o índice de privação socioeconômica (construído por meio do Censo dos Estados Unidos de 1990 e 2000, considerando: educação, emprego, habitação, composição ética/racial, entre outros) e os indicadores da doença, mais evidentes em áreas metropolitanas.

Os autores supracitados, por meio da análise de mapas, destacaram que a disponibilidade de profissionais de saúde exerce importante influência sobre os indicadores de câncer de mama. Estes profissionais demandam maior número de exames de mamografia e esta ação pode contribuir para a expansão do número de diagnósticos da doença. Por sua vez, destacaram que áreas com alto índice de privação socioeconômica possuem pouca disponibilidade de profissionais de saúde e acesso limitado à mamografia, podendo levar a um menor número de diagnósticos da doença.

De maneira similar, a incidência e mortalidade por câncer de mama foram analisadas por Beysebayev et al. (2015) entre 1999 e 2013 no Cazaquistão. No período de análise, a incidência da doença aumentou em grandes cidades do país (como Astana e Almaty), enquanto a mortalidade por esse tipo de câncer diminuiu, com concentração nas regiões de Pavlodar e Almaty. As diferenças geográficas na incidência e mortalidade por esse agravo, observados por meio da análise de mapas no estudo, podem refletir as inequidades no acesso aos serviços de saúde, indicando a necessidade de políticas mais ativas acerca do rastreamento mamográfico e cuidados clínicos em algumas regiões do Cazaquistão.

Herrmann et al. (2015) analisaram a mortalidade por quatro tipos de cân- 
cer feminino: mama, ovário, cervical e uterino, com base em dados coletados no período de 1969 a 2011 na Suíça. Não foram encontradas diferenças geográficas significativas entre as regiões. Além disso, as variáveis urbanização, utilizada como proxy para medir a educação e o acesso aos serviços de saúde, e o idioma falado em cada região da Suíça (alemão, francês ou italiano) não tiveram influência significativa sobre a mortalidade por câncer feminino.

Madhu et al. (2016) analisaram um total de 1.090 registros de câncer de mama para 29 localidades na Índia nos anos de 2007 a 2011. A análise dos mapas revelou que áreas urbanas de Mysore apresentaram maior risco de desenvolvimento da doença. Uma possível explicação está no significativo número de indústrias que se estabeleceram dentro e nas proximidades dessa região, contribuindo para sua rápida urbanização e mudança no estilo de vida da população. Concluíram que agrupamentos dessa doença são observados em regiões urbanas, sendo que nas áreas rurais a incidência desse tipo de câncer não segue um padrão de distribuição espacial.

Na Espanha, Ocaña-Riola et al. (2016) realizaram um mapeamento geográfico a partir dos dados de mortalidade por câncer de mama em mulheres (nas faixas etárias de 15 a 44 anos, 45 a 64 anos e 75 a 84 anos) dos municípios da Andaluzia (sul da Espanha), entre 1981 e 2012. No período de análise, as cidades apresentaram estabilidade ou redução da taxa de mortalidade, devido ao aumento da cobertura das mamografias. Além disso, não foram identificadas aglomerações significativas na região pesquisada.

Já Xia et al. (2016) avaliaram dados de mortalidade por câncer de mama em 31 províncias da China em três diferentes períodos: de 1973 a 1975, 1990 a 1992 e 2004 a 2005. Baixas taxas de mortalidade pela doença foram observadas na China Ocidental (Noroeste e Sudoeste), enquanto altas taxas foram encontradas no Nordeste da China. A correlação positiva observada entre a mortalidade por essa doença e Produto Interno Bruto, número de hospitais, de camas hospitalares (por 100 mil habitantes), de médicos (por 100 mil habitantes) e de filhos vivos de mulheres entre 15 e 64 anos sugeriram a existência de disparidades na prevenção, diagnóstico e cuidados de saúde no país, que se refletiram em sua distribuição espacial.

Em nível nacional, Wünsch Filho \& Moncau (2002) analisaram a distribuição geográfica e a tendência temporal da mortalidade por câncer, incluindo o de mama, entre 1980 e 1995 no Brasil. Em 1995, a taxa de mortalidade por câncer de mama observada nas regiões Sul e Sudeste (em torno de 9 por 100 mil habitantes) foi duas vezes àquela observada nas demais áreas do país. Entre os inúmeros fatores de risco que poderiam contribuir para explicar as diferenças geográficas de mortalidade, destacaram o fato de as mulheres do Norte, Nordeste e Centro-Oeste terem filhos em idade mais precoce e um maior número médio de filhos, podendo esse fato estar agindo como fator de proteção para o câncer de mama. Ao contrário, as mulheres do Sul e Sudeste, que vivem em sua maior proporção em áreas urbanas, tendem a ter filhos em idades mais avançadas, o que poderia explicar a alta mortalidade da doença.

Santos et al. (2009) utilizaram dados de mortalidade por câncer de mama e colo de útero no ano de 2004 para todo o Brasil. Por meio da análise de mapas, foi observada alta concentração de óbitos nos estados do Rio de Janeiro, São Paulo e Rio Grande do Sul, ou seja, em áreas com melhores condições socioeconômicas. Concluíram que a mortalidade pela doença mostrou grande variação entre as regiões brasileiras, como reflexo da incidência, do acesso aos serviços de saúde e da qualidade de registro dos óbitos. 
O mesmo foi observado no estudo de Zapponi \& Melo (2010), com base em dados da mortalidade por câncer de mama e uterino no período de 2003 a 2007 no Brasil. Constataram que a mortalidade por essa doença foi maior nas regiões de maior desenvolvimento do país; no entanto, destacaram que a elevada proporção de óbitos mal definidos observados nos municípios de baixo nível socioeconômico compromete a qualidade do registro nessas regiões. Apontaram a necessidade da consolidação de políticas de saúde voltadas para a mulher, de maneira a viabilizar seu acesso aos serviços de saúde, melhorar a qualidade da assistência e a prevenção, visando a detecção precoce destas neoplasias.

Já entre os autores que utilizaram como instrumento metodológico a Análise Exploratória dos Dados Espaciais (AEDE), destaca-se Goovaerts (2006), que investigou a taxa de mortalidade por câncer de mama e do pâncreas no período de 1970 a 1994 em 295 condados do nordeste dos Estados Unidos. Padrões locais de associação espacial do tipo Baixo-Baixo (ou seja, áreas com baixa mortalidade por câncer de mama rodeadas por regiões com também baixa mortalidade pela doença) foram encontrados nos condados ao sul da área estudada. Já padrões locais de associação espacial do tipo Alto-Alto (ou seja, regiões com alta mortalidade por câncer de mama rodeadas por regiões com também alta mortalidade por esta neoplasia) foram evidenciados nos condados à leste da área estudada. Concluíram que a identificação dessas áreas permite uma alocação mais eficiente dos recursos para prevenção da doença.

Perinetti (2015) investigou o comportamento das taxas de mortalidade por câncer de mama na Argentina, entre 2009 e 2011, aplicando a AEDE. As maiores taxas de mortalidade pela doença ocorreram em áreas com melhores indicadores socioeconômicos, como menor índice de necessidades básicas insatisfeitas (NBI), maior porcentagem da população com plano de saúde e de mulheres que realizaram mamografia. Além disso, as maiores taxas de mortalidade por câncer de mama ocorreram nas localidades em que a qualidade do registro de óbitos é melhor (menor percentual de mortes mal definidas). Concluíram que a identificação dessas áreas é necessária para avaliar a equidade do sistema de saúde e o impacto que as políticas sanitárias provocam nos diferentes cenários e contextos do país.

Já Zhou et al. (2015) examinaram a distribuição da incidência de câncer feminino, incluindo o câncer de mama, entre 2007 e 2012 em Shenzhen, China. A autocorrelação espacial foi detectada por meio do teste I de Moran $(0,372)$, sendo encontrados padrões locais de associações espaciais dos tipos BaixoBaixo e Alto-Alto, respectivamente, na parte oeste e no centro-sul de Shenzhen. A incidência de câncer de mama foi maior em áreas urbanas, sendo resultado da combinação de diversos fatores, destacando genéticos, ambientais (poluição do ar), comportamentais (alimentação inadequada e inatividade física) e socioeconômicos, relacionados a um maior número de mulheres que realizam mamografia, aumentando assim a detecção precoce.

Em termos nacionais, Müller (2009) buscou descrever padrões de mortalidade por câncer de mama e de colo de útero de mulheres (com idade mínima de 15 anos) dos 96 distritos administrativos do município de São Paulo, no período de 1996 a 2006. A análise espacial mostrou que as regiões mais centrais, que contam com maior disponibilidade de recursos e equipamentos de saúde, foram as áreas de maior risco para o câncer de mama. Concluíram que apesar dos avanços tecnológicos que propiciam uma melhora do diagnóstico e tratamento da doença, ainda há demora no diagnóstico, levando a altos 
coeficientes de mortalidade por câncer de mama em São Paulo. 
Tabela 1: Sistematização da literatura internacional e nacional referente a estudos sobre incidência e mortalidade por câncer de mama

\begin{tabular}{|c|c|c|c|c|c|}
\hline \multicolumn{6}{|c|}{ Literatura Internacional } \\
\hline $\begin{array}{l}\text { Autor(es)/ } \\
\text { (ano) }\end{array}$ & Amostra & Método & Variável & $\begin{array}{l}\text { Utilização de } \\
\text { controles }\end{array}$ & Resultados \\
\hline $\begin{array}{l}\text { Fukuda } \\
\text { et al. } \\
(2005)\end{array}$ & $\begin{array}{l}\text { Dados mu- } \\
\text { nicipais do } \\
\text { Japão (n }= \\
3360) \text { de } \\
1993 \text { a } 1998\end{array}$ & $\begin{array}{l}\text { Mapeamento } \\
\text { geográfico }\end{array}$ & $\begin{array}{l}\text { Taxa de mor- } \\
\text { talidade por } \\
\text { câncer de } \\
\text { mama (mulhe- } \\
\text { res) e de cólon } \\
\text { e pulmão } \\
\text { (homens) }\end{array}$ & Não & $\begin{array}{l}\text { As aglomerações da mortalidade } \\
\text { por câncer de mama ocorreram } \\
\text { em municípios urbanos, com } \\
\text { mulheres que possuíam nível de } \\
\text { renda e educação mais altos, li- } \\
\text { gados a fatores como hábitos ali- } \\
\text { mentares inadequados e baixo } \\
\text { número de filhos. }\end{array}$ \\
\hline $\begin{array}{l}\text { Vieira } \\
\text { et al. } \\
(2008)\end{array}$ & $\begin{array}{l}1.631 \text { parti- } \\
\text { cipantes, em } \\
\text { Cape Cod, } \\
\text { Massachu- } \\
\text { setts (EUA) } \\
\text { de } 1947 \text { a } \\
1993\end{array}$ & $\begin{array}{l}\text { Mapeamento } \\
\text { geográfico }\end{array}$ & $\begin{array}{l}\text { Casos de cân- } \\
\text { cer de mama }\end{array}$ & Não & $\begin{array}{l}\text { Forte associação entre residir } \\
\text { perto da Reserva Militar de Mas- } \\
\text { sachusetts entre } 1947 \text { e } 1956 \text { e } \\
\text { o risco de diagnóstico de cân- } \\
\text { cer de mama entre } 1983 \text { e } 1993 \text {, } \\
\text { tendo como possíveis determi- } \\
\text { nantes da doença causas ambi- } \\
\text { entais (ingestão de água conta- } \\
\text { minada e poluição do ar perto } \\
\text { da reserva militar). }\end{array}$ \\
\hline $\begin{array}{l}\text { Alvarez } \\
\text { et al. } \\
(2009)\end{array}$ & $\begin{array}{l}2.438 \text { novos } \\
\text { casos de cân- } \\
\text { cer de mama } \\
\text { e } 1.451 \text { de } \\
\text { colo de útero } \\
\text { em Cuba en- } \\
\text { tre } 1999 \text { e } \\
2003\end{array}$ & $\begin{array}{l}\text { Mapeamento } \\
\text { geográfico }\end{array}$ & $\begin{array}{l}\text { Incidência } \\
\text { de câncer de } \\
\text { mama e de } \\
\text { colo de útero }\end{array}$ & Não & $\begin{array}{l}\text { Alto risco de incidência de cân- } \\
\text { cer de mama nos municípios } \\
\text { da Província de Havana (nível } \\
\text { de urbanização de } 100 \% \text { ), com } \\
\text { população predominantemente } \\
\text { branca (historicamente relacio- } \\
\text { nado ao status socioeconômico), } \\
\text { número pequeno de filhos e } \\
\text { idade avançada na primeira gra- } \\
\text { videz. }\end{array}$ \\
\hline
\end{tabular}


Tabela 1: Sistematização da literatura internacional e nacional referente a estudos sobre incidência e mortalidade por câncer de mama (continuação)

Literatura Internacional

\begin{tabular}{|c|c|c|c|c|c|}
\hline $\begin{array}{c}\text { Autor }(e s) / \\
(\text { ano) }\end{array}$ & Amostra & Método & Variável & $\begin{array}{c}\text { Utilização de } \\
\text { controles }\end{array}$ & Resultados \\
\hline $\begin{array}{l}\text { Chien } \\
\text { et al. } \\
(2012)\end{array}$ & $\begin{array}{l}189.574 \text { mulheres com } \\
\text { diagnóstico inicial, } \\
142.338 \text { mulheres com } \\
\text { diagnóstico avançado } \\
\text { e } 57.683 \text { mortes por } \\
\text { câncer de mama nos } \\
\text { Estados Unidos entre } \\
1988 \text { e } 2008\end{array}$ & $\begin{array}{l}\text { Mapeamento } \\
\text { geográfico }\end{array}$ & $\begin{array}{l}\text { Incidência } \\
\text { (em está- } \\
\text { gio inicial e } \\
\text { avançado) e } \\
\text { mortalidade } \\
\text { por câncer de } \\
\text { mama }\end{array}$ & $\begin{array}{l}\text { Sim: disponi- } \\
\text { bilidade de } \\
\text { profissionais } \\
\text { de saúde e } \\
\text { índice de } \\
\text { privação soci- } \\
\text { oeconômica }\end{array}$ & $\begin{array}{l}\text { Associação positiva entre a disponibilidade de pro- } \\
\text { fissionais de saúde (definido como o número de } \\
\text { médicos de cuidado primário por } 100 \text { mil mulhe- } \\
\text { res na faixa etária de } 40 \text { anos ou mais) e os indi- } \\
\text { cadores do câncer de mama (incidência e morta- } \\
\text { lidade). Relação negativa entre o índice de pri- } \\
\text { vação socioeconômica (construído por meio do } \\
\text { Censo dos Estados Unidos de } 1990 \text { e } 2000 \text {, consi- } \\
\text { derando: educação, emprego, habitação, composi- } \\
\text { ção ética/racial, entre outros) e os indicadores da } \\
\text { doença, mais evidentes em áreas metropolitanas. }\end{array}$ \\
\hline $\begin{array}{l}\text { Beysebaye } \\
\text { et al. } \\
(2015)\end{array}$ & $\begin{array}{l}45.891 \text { novos casos e } \\
20.122 \text { mortes por cân- } \\
\text { cer de mama no Ca- } \\
\text { zaquistão entre } 1999 \text { e } \\
2013\end{array}$ & $\begin{array}{l}\text { Mapeamento } \\
\text { geográfico }\end{array}$ & $\begin{array}{l}\text { Incidência e } \\
\text { mortalidade } \\
\text { por câncer de } \\
\text { mama }\end{array}$ & Não & $\begin{array}{l}\text { A incidência da doença aumentou em grandes ci- } \\
\text { dades do país (como Astana e Almaty), enquanto } \\
\text { que a mortalidade por esse tipo de câncer dimi- } \\
\text { nuiu, com concentração nas regiões de Pavlodar e } \\
\text { Almaty. As diferenças geográficas na incidência e } \\
\text { mortalidade por esse agravo podem refletir as ine- } \\
\text { quidades no acesso aos serviços de saúde. }\end{array}$ \\
\hline $\begin{array}{l}\text { Herrmann } \\
\text { et al. } \\
(2015)\end{array}$ & $\begin{array}{l}\text { Dados coletados na } \\
\text { Suíça entre } 1969 \text { e } \\
2011\end{array}$ & $\begin{array}{l}\text { Mapeamento } \\
\text { geográfico }\end{array}$ & $\begin{array}{l}\text { Mortalidade } \\
\text { por quatro } \\
\text { tipos de cân- } \\
\text { cer feminino: } \\
\text { mama, ovário, } \\
\text { cervical e } \\
\text { uterino }\end{array}$ & $\begin{array}{lr}\text { Sim: } & \text { urba- } \\
\text { nização } & \text { e } \\
\text { idioma falado }\end{array}$ & $\begin{array}{l}\text { Não foram encontradas diferenças geográficas sig- } \\
\text { nificativas entre as regiões. As variáveis urbaniza- } \\
\text { ção, utilizada como proxy para medir a educação } \\
\text { e o acesso aos serviços de saúde, e o idioma falado } \\
\text { em cada região da Suíça (alemão, francês ou ita- } \\
\text { liano) não tiveram influência significativa sobre a } \\
\text { mortalidade por câncer feminino. }\end{array}$ \\
\hline
\end{tabular}


Tabela 1: Sistematização da literatura internacional e nacional referente a estudos sobre incidência e mortalidade por câncer de mama (continuação)

\begin{tabular}{|c|c|c|c|c|c|}
\hline \multicolumn{6}{|c|}{ Literatura Internacional } \\
\hline $\begin{array}{c}\text { Autor }(\text { es }) / \\
\text { (ano) }\end{array}$ & Amostra & Método & Variável & $\begin{array}{l}\text { Utilização de } \\
\text { controles }\end{array}$ & Resultados \\
\hline $\begin{array}{l}\text { Ocaña- } \\
\text { Riola } \\
\text { et al. } \\
(2016)\end{array}$ & $\begin{array}{l}26.907 \text { mortes registra- } \\
\text { das por câncer de mama } \\
\text { em mulheres dos muni- } \\
\text { cípios da Andaluzia (sul } \\
\text { da Espanha) entre } 1981 \text { e } \\
2012 \text {. }\end{array}$ & $\begin{array}{l}\text { Mapeamento } \\
\text { geográfico }\end{array}$ & $\begin{array}{l}\text { Taxa de } \\
\text { mortali- } \\
\text { dade por } \\
\text { câncer de } \\
\text { mama }\end{array}$ & Não & $\begin{array}{l}\text { As cidades apresentaram estabilidade ou redução } \\
\text { da taxa de mortalidade, devido ao aumento da co- } \\
\text { bertura das mamografias. Além disso, não foram } \\
\text { identificadas aglomerações significativas na região } \\
\text { pesquisada. }\end{array}$ \\
\hline $\begin{array}{l}\text { Xia et al. } \\
(2016)\end{array}$ & $\begin{array}{l}\text { Dados da China em três } \\
\text { diferentes períodos: de } \\
1973 \text { a } 1975 \text { ( } \mathrm{n}=850 \mathrm{mi}- \\
\text { lhões de pessoas), } 1990 \mathrm{a} \\
1992 \text { ( } \mathrm{n}=335 \text { milhões de } \\
\text { pessoas por ano) e } 2004 \mathrm{a} \\
2005 \text { (n=143 milhões de } \\
\text { pessoas por ano) }\end{array}$ & $\begin{array}{l}\text { Mapeamento } \\
\text { geográfico }\end{array}$ & $\begin{array}{l}\text { Mortalidade } \\
\text { por câncer } \\
\text { de mama }\end{array}$ & $\begin{array}{l}\text { Sim: PIB per ca- } \\
\text { pita, número de } \\
\text { hospitais, de ca- } \\
\text { mas hospitalares, } \\
\text { de médicos e de fi- } \\
\text { lhos vivos de mu- } \\
\text { lheres entre } 15 \text { e } \\
64 \text { anos }\end{array}$ & $\begin{array}{l}\text { Baixas taxas de mortalidade pela doença foram } \\
\text { observadas na China Ocidental (Noroeste e Sudo- } \\
\text { este), enquanto altas taxas foram encontradas no } \\
\text { Nordeste da China. Correlação positiva observada } \\
\text { entre a mortalidade por essa doença e Produto In- } \\
\text { terno Bruto, número de hospitais, de camas hospi- } \\
\text { talares (por } 100 \text { mil habitantes), de médicos (por } \\
100 \text { mil habitantes) e de filhos vivos de mulheres } \\
\text { entre } 15 \text { e } 64 \text { anos. }\end{array}$ \\
\hline $\begin{array}{l}\text { Goovaerts } \\
(2006)\end{array}$ & $\begin{array}{l}\text { Dados de } 295 \text { condados } \\
\text { do nordeste dos Esta- } \\
\text { dos Unidos entre } 1970 \text { e } \\
1994\end{array}$ & $\begin{array}{l}\text { Análise Ex- } \\
\text { ploratória } \\
\text { de Dados } \\
\text { Espaciais }\end{array}$ & $\begin{array}{l}\text { Mortalidade } \\
\text { por cân- } \\
\text { cer de } \\
\text { mama e do } \\
\text { pâncreas }\end{array}$ & Não & $\begin{array}{l}\text { Padrões locais de associação espacial do tipo Baixo- } \\
\text { Baixo (ou seja, áreas com baixa mortalidade por } \\
\text { câncer de mama rodeadas por regiões com tam- } \\
\text { bém baixa mortalidade pela doença) foram encon- } \\
\text { trados nos condados ao sul da área estudada. Já } \\
\text { padrões locais de associação espacial do tipo Alto- } \\
\text { Alto (ou seja, regiões com alta mortalidade por cân- } \\
\text { cer de mama rodeadas por regiões com também } \\
\text { alta mortalidade por esta neoplasia) foram eviden- } \\
\text { ciados nos condados à leste da área estudada. }\end{array}$ \\
\hline
\end{tabular}


Tabela 1: Sistematização da literatura internacional e nacional referente a estudos sobre incidência e mortalidade por câncer de mama (continuação)

\begin{tabular}{|c|c|c|c|c|c|}
\hline \multicolumn{6}{|c|}{ Literatura Internacional } \\
\hline $\begin{array}{c}\text { Autor }(\text { es }) / \\
\text { (ano) }\end{array}$ & Amostra & Método & Variável & $\begin{array}{c}\text { Utilização de } \\
\text { controles }\end{array}$ & Resultados \\
\hline $\begin{array}{l}\text { Perinetti } \\
(2015)\end{array}$ & $\begin{array}{l}16.311 \text { mortes } \\
\text { por câncer } \\
\text { de mama na } \\
\text { Argentina entre } \\
2009 \text { e } 2011\end{array}$ & $\begin{array}{l}\text { Análise Ex- } \\
\text { ploratória } \\
\text { de Dados } \\
\text { Espaciais }\end{array}$ & $\begin{array}{lr}\text { Taxa de } & \text { mor- } \\
\text { talidade } & \text { por } \\
\text { câncer } & \text { de } \\
\text { mama } & \end{array}$ & $\begin{array}{l}\text { Sim: variáveis demo- } \\
\text { gráficas, socioeconô- } \\
\text { micas, utilização, } \\
\text { acesso geográfico e } \\
\text { oferta de serviços de } \\
\text { saúde. }\end{array}$ & $\begin{array}{l}\text { As maiores taxas de mortalidade por câncer de } \\
\text { mama ocorreram em áreas com melhores indicado- } \\
\text { res socioeconômicos, como menor índice de neces- } \\
\text { sidades básicas insatisfeitas (NBI), maior porcenta- } \\
\text { gem da população com plano de saúde, de mulhe- } \\
\text { res que realizaram mamografia e nas localidades } \\
\text { em que a qualidade do registro de óbitos é melhor } \\
\text { (menor percentual de mortes mal definidas). }\end{array}$ \\
\hline $\begin{array}{l}\text { Zhou } \\
\text { et al. } \\
(2015)\end{array}$ & $\begin{array}{l}5.511 \text { casos } \\
\text { de câncer de } \\
\text { mama em } \\
\text { Shenzhen } \\
\text { (China) entre } \\
2007 \text { e } 2012\end{array}$ & $\begin{array}{l}\text { Análise Ex- } \\
\text { ploratória } \\
\text { de Dados } \\
\text { Espaciais }\end{array}$ & $\begin{array}{l}\text { Incidência } \\
\text { de câncer } \\
\text { feminino, } \\
\text { incluindo o } \\
\text { câncer de } \\
\text { mama }\end{array}$ & Sim: idade & $\begin{array}{l}\text { A incidência de câncer de mama foi maior em } \\
\text { áreas urbanas, sendo resultado da combinação de } \\
\text { diversos fatores, destacando genéticos, ambientais } \\
\text { (poluição do ar), comportamentais (alimentação } \\
\text { inadequada e inatividade física) e socioeconômi- } \\
\text { cos, relacionados a um maior número de mulhe- } \\
\text { res que realizam mamografia, aumentando assim } \\
\text { a detecção precoce. }\end{array}$ \\
\hline
\end{tabular}


Tabela 1: Sistematização da literatura internacional e nacional referente a estudos sobre incidência e mortalidade por câncer de mama (continuação)

\begin{tabular}{|c|c|c|c|c|c|}
\hline \multicolumn{6}{|c|}{ Literatura Nacional } \\
\hline $\begin{array}{l}\text { Autor }(\text { es }) / \\
\text { (ano) }\end{array}$ & Amostra & Método & Variável & $\begin{array}{c}\text { Utilização de } \\
\text { controles }\end{array}$ & Resultados \\
\hline $\begin{array}{l}\text { Wünsch } \\
\text { Filho } \\
\& \\
\text { Mon- } \\
\text { cau } \\
(2002)\end{array}$ & $\begin{array}{l}\text { Dados extraídos das de- } \\
\text { clarações de óbito incluí- } \\
\text { das na base de morta- } \\
\text { lidade do Ministério da } \\
\text { Saúde entre } 1980 \text { e } 1995 \\
\text { (Brasil) }\end{array}$ & $\begin{array}{l}\text { Mapeamento } \\
\text { geográfico }\end{array}$ & $\begin{array}{l}\text { Taxas de } \\
\text { mortalidade } \\
\text { por câncer, } \\
\text { incluindo o de } \\
\text { mama }\end{array}$ & Não & $\begin{array}{l}\text { Em 1995, a taxa de mortalidade por cân- } \\
\text { cer de mama observada nas regiões Sul e } \\
\text { Sudeste (em torno de } 9 \text { por } 100 \text { mil habi- } \\
\text { tantes) foi duas vezes àquela observada nas } \\
\text { demais áreas do país. As mulheres do Sul } \\
\text { e Sudeste, que vivem em sua maior propor- } \\
\text { ção em áreas urbanas, tendem a ter filhos } \\
\text { em idades mais avançadas, o que poderia } \\
\text { explicar a alta mortalidade da doença. }\end{array}$ \\
\hline $\begin{array}{l}\text { Santos } \\
\text { et al. } \\
(2009)\end{array}$ & $\begin{array}{l}\text { Dados secundários do } \\
\text { Sistema de Informação } \\
\text { sobre Mortalidade em } \\
2004 \text { (Brasil) }\end{array}$ & $\begin{array}{l}\text { Mapeamento } \\
\text { geográfico }\end{array}$ & $\begin{array}{l}\text { Mortalidade } \\
\text { por câncer de } \\
\text { mama e colo } \\
\text { de útero }\end{array}$ & Não & $\begin{array}{l}\text { Alta concentração de óbitos nos estados do } \\
\text { Rio de Janeiro, São Paulo e Rio Grande do } \\
\text { Sul, ou seja, em áreas com melhores condi- } \\
\text { ções socioeconômicas. }\end{array}$ \\
\hline $\begin{array}{l}\text { Zapponi } \\
\& \\
\text { Melo } \\
(2010)\end{array}$ & $\begin{array}{l}51.233 \text { óbitos por câncer } \\
\text { de mama e } 22.394 \text { óbitos } \\
\text { por câncer do colo ute- } \\
\text { rino entre } 2003 \text { a } 2007 \\
\text { (Brasil) }\end{array}$ & $\begin{array}{l}\text { Mapeamento } \\
\text { geográfico }\end{array}$ & $\begin{array}{l}\text { Mortalidade } \\
\text { por câncer } \\
\text { de mama e } \\
\text { uterino }\end{array}$ & Não & $\begin{array}{l}\text { Constataram que a mortalidade por essa } \\
\text { doença foi maior nas regiões de maior de- } \\
\text { senvolvimento do país; no entanto, desta- } \\
\text { caram que a elevada proporção de óbitos } \\
\text { mal definidos observados nos municípios } \\
\text { de baixo nível socioeconômico compromete } \\
\text { a qualidade do registro nessas regiões. }\end{array}$ \\
\hline
\end{tabular}


Tabela 1: Sistematização da literatura internacional e nacional referente a estudos sobre incidência e mortalidade por câncer de mama (continuação)

\begin{tabular}{|c|c|c|c|c|c|}
\hline \multicolumn{6}{|c|}{ Literatura Nacional } \\
\hline $\begin{array}{l}\operatorname{Autor}(\mathrm{es}) / \\
(\text { ano })\end{array}$ & Amostra & Método & Variável & $\begin{array}{c}\text { Utilização de } \\
\text { controles }\end{array}$ & Resultados \\
\hline $\begin{array}{l}\text { Müller } \\
(2009)\end{array}$ & $\begin{array}{l}\text { Dados dos } 96 \\
\text { distritos admi- } \\
\text { nistrativos do } \\
\text { município de } \\
\text { São Paulo de } \\
1996 \text { a } 2006\end{array}$ & $\begin{array}{l}\text { Análise } \\
\text { Explora- } \\
\text { tória de } \\
\text { Dados } \\
\text { Espaciais }\end{array}$ & $\begin{array}{l}\text { Mortalidade } \\
\text { por câncer de } \\
\text { mama e de } \\
\text { colo de útero } \\
\text { de mulheres }\end{array}$ & $\begin{array}{l}\text { Sim: triênios de ocorrên- } \\
\text { cia dos óbitos } \\
\text { 1999-2001, 2004-2006), } \\
\text { idade, causa básica da morte, } \\
\text { local de domicílio, índice de } \\
\text { inclusão/exclusão }\end{array}$ & $\begin{array}{l}\text { Regiões mais centrais, que contam com } \\
\text { maior disponibilidade de recursos e equi- } \\
\text { pamentos de saúde, foram as áreas de } \\
\text { maior risco para o câncer de mama. }\end{array}$ \\
\hline $\begin{array}{l}\text { Bello } \\
(2010)\end{array}$ & $\begin{array}{l}\text { Dados do Es- } \\
\text { tado do Rio de } \\
\text { Janeiro entre } \\
2001 \text { e } 2006\end{array}$ & $\begin{array}{l}\text { Análise } \\
\text { Explora- } \\
\text { tória de } \\
\text { Dados } \\
\text { Espaciais }\end{array}$ & $\begin{array}{l}\text { Taxa de } \\
\text { mortalidade } \\
\text { por câncer } \\
\text { de mama } \\
\text { feminino }\end{array}$ & $\begin{array}{l}\text { Sim: idade, raça, estado ci- } \\
\text { vil, nível educacional, renda } \\
\text { média do trabalho princi- } \\
\text { pal das pessoas adultas de } \\
\text { cada município, índice de } \\
\text { mamógrafos por município, } \\
\text { Índice de Desenvolvimento } \\
\text { Humano Municipal, Índice } \\
\text { Firjan de Desenvolvimento } \\
\text { Municipal, cobertura da po- } \\
\text { pulação por saúde comple- } \\
\text { mentar, média de consultas } \\
\text { nas especialidades básicas e } \\
\text { despesa municipal de saúde } \\
\text { por habitante }\end{array}$ & $\begin{array}{l}\text { A dependência espacial foi constatada por } \\
\text { meio do cálculo I de Moran para a taxa de } \\
\text { mortalidade por câncer de mama do triênio } \\
2001 \text { a } 2003 \text {. As variáveis que melhor ex- } \\
\text { plicaram os aglomerados espaciais foram a } \\
\text { renda média do trabalho principal das pes- } \\
\text { soas adultas de cada município e o índice } \\
\text { de mamógrafos por município. }\end{array}$ \\
\hline
\end{tabular}


Por sua vez, Bello (2010) avaliou a existência de dependência espacial na taxa de mortalidade por câncer de mama feminino no Estado do Rio de Janeiro, no período de 2001 a 2006, e possíveis variáveis explicativas: idade, raça, estado civil, nível educacional, renda média do trabalho principal das pessoas adultas de cada município, índice de mamógrafos por município, Índice de Desenvolvimento Humano Municipal, Índice Firjan de Desenvolvimento Municipal, cobertura da população por saúde complementar, média de consultas nas especialidades básicas e despesa municipal de saúde por habitante. A dependência espacial foi constatada por meio do cálculo I de Moran para a taxa de mortalidade do triênio 2001 a 2003. As variáveis que melhor explicaram os aglomerados espaciais foram a renda média do trabalho principal das pessoas adultas de cada município e o índice de mamógrafos por município.

A partir desta revisão de literatura, observa-se que tanto a incidência quanto a mortalidade por câncer de mama estiveram associados a determinantes reprodutivos, de comportamento/estilo de vida e sobretudo, àqueles relacionados ao local de residência (urbano/rural) e ao status socioeconômico das mulheres. Dessa forma, as desigualdades regionais identificadas por meio da análise espacial podem refletir inequidades no acesso aos serviços de saúde, no que diz respeito a prevenção, diagnóstico e tratamento da doença, sugerindo a necessidade de políticas públicas locais e a melhor alocação de recursos para cada área geográfica.

\section{Caracterização dos Fatores de Gestão em Saúde Relacionados ao Câncer de Mama por Regiões do Brasil}

O câncer de mama, assim como as demais neoplasias malignas, é resultado de uma proliferação incontrolável de células anormais, decorrentes de alterações genéticas que podem provocar mudanças no crescimento celular ou na morte celular programada, levando ao surgimento do tumor. Por ser classificado como um problema de saúde pública, ao apresentar altas taxas de incidência e mortalidade, o modelo assistencial das mulheres diagnosticadas com câncer de mama deve integrar os diferentes níveis de atenção (primária, secundária e terciária) (Brasil 2013).

O modelo assistencial deve garantir o acesso aos serviços de saúde e cuidado integral, envolvendo ações de prevenção, tratamento, cuidados paliativos, entre outros, de modo a aumentar a sobrevida do paciente com diagnóstico da neoplasia mamária (Brasil 2013, Rodrigues et al. 2015).

As ações da Atenção Primária/Atenção Básica envolvem o cadastro e identificação da população prioritária, com realização de exame clínico das mamas para detecção de lesões palpáveis e encaminhamento para exame de mamografia (atenção secundária), caso haja necessidade. A Atenção Básica é realizada por todo o território nacional, de forma descentralizada, sendo que as Unidades Básicas de Saúde (UBS), onde atuam as equipes do Programa Saúde da Família, constituem a principal porta de entrada para o SUS (Brasil 2013, Teixeira et al. 2017). 
Tabela 2: Caracterização dos fatores de gestão em saúde relacionados ao câncer de mama (em números), Regiões do Brasil, 2012 a 2017

\begin{tabular}{lcccccc}
\hline Ano & Total & Norte & Nordeste & Sudeste & Sul & Centro-Oeste \\
\hline \multicolumn{5}{c}{ Equipes de Saúde } \\
\hline 2012 & 41.776 & 3.644 & 15.897 & 13.612 & 5.619 & 3.004 \\
2013 & 44.566 & 3.863 & 17.017 & 14.431 & 6.037 & 3.218 \\
2014 & 48.892 & 4.315 & 18.215 & 15.974 & 6.911 & 3.477 \\
2015 & 51.221 & 4.589 & 18.776 & 16.758 & 7.445 & 3.653 \\
2016 & 52.165 & 4.670 & 18.867 & 17.388 & 7.545 & 3.695 \\
2017 & 54.205 & 4.829 & 19.584 & 18.108 & 7.808 & 3.876 \\
\hline \multicolumn{7}{c}{ Mamógrafos ${ }^{1}$} \\
\hline 2012 & 1.926 & 107 & 475 & 808 & 378 & 158 \\
2013 & 2.159 & 111 & 595 & 877 & 401 & 175 \\
2014 & 2.384 & 141 & 715 & 913 & 426 & 189 \\
2015 & 2.446 & 168 & 705 & 933 & 444 & 196 \\
2016 & 2.447 & 170 & 680 & 949 & 453 & 195 \\
2017 & 2.529 & 180 & 692 & 982 & 479 & 196 \\
\hline \multicolumn{7}{c}{ Hospitais ${ }^{2}$} \\
\hline 2012 & 6.296 & 528 & 1.748 & 2.199 & 1.053 & 768 \\
2013 & 6.297 & 526 & 1.778 & 2.180 & 1.041 & 772 \\
2014 & 6.340 & 539 & 1.806 & 2.191 & 1.033 & 771 \\
2015 & 6.152 & 529 & 1.763 & 2.097 & 1.012 & 751 \\
2016 & 6.097 & 526 & 1.760 & 2.065 & 1.006 & 740 \\
2017 & 6.161 & 531 & 1.795 & 2.074 & 1.003 & 758 \\
\hline \multicolumn{7}{c}{ Leitos de internação } \\
\hline 2012 & 326.063 & 24.313 & 98.629 & 125.438 & 52.585 & 25.098 \\
2013 & 321.413 & 24.109 & 97.655 & 122.058 & 52.923 & 24.668 \\
2014 & 319.283 & 24.298 & 96.538 & 120.354 & 53.357 & 24.736 \\
2015 & 311.917 & 24.164 & 94.210 & 117.173 & 52.145 & 24.225 \\
2016 & 307.805 & 24.342 & 93.815 & 113.984 & 51.514 & 24.150 \\
\hline & 303.183 & 24.191 & 93.603 & 110.494 & 51.392 & 23.503 \\
\hline
\end{tabular}

Fonte: Brasil (2018). Elaboração própria. Dados extraídos do Cadastro Nacional de

Estabelecimentos de Saúde (CNES) do SUS de dezembro de cada ano.

${ }^{1}$ Considerando as categorias: Mamógrafo com comando simples, Mamógrafo com estereotaxia e Mamógrafo computadorizado, disponíveis no SUS

${ }^{2}$ Considerando as categorias: Hospital especializado e Hospital geral.

${ }^{3}$ Considerando apenas Leitos de internação do SUS. 
Segundo dados do Cadastro Nacional de Estabelecimentos de Saúde (CNES) do SUS, o número total de equipes de saúde no Brasil passou de 41,78 mil em 2012 para 54,21 mil em 2017. As equipes de saúde se distribuem por todo o território nacional, sendo que o Nordeste concentrou a maior quantidade desta variável (19,58 mil), enquanto que o Centro-Oeste apresentou o menor número (3,88 mil), em 2017 (Tabela 2).

Por sua vez, a Atenção Secundária envolve unidades ambulatoriais e serviços de apoio diagnóstico e terapêutico, responsáveis pela oferta de consultas e exames especializados. No caso do câncer de mama, a realização de mamografia e biópsia diagnóstica é realizada nesse nível de atenção. Caso o laudo aponte doença maligna, é feito encaminhamento para a cirurgia (Atenção Terciária) Brasil (2013), Azevedo et al. (2014).

De acordo com dados do SUS (Tabela 2), o número de equipamentos de mamografia passou de 1,93 mil em 2012 para 2,53 mil em 2017. O Sudeste e o Norte do país apresentaram as maiores e menores quantidade destes aparelhos, sendo de 982 e 180 unidades respectivamente, no ano de 2017.

Por fim, a Atenção Terciária é composta pelos serviços de apoio diagnóstico e terapêutico hospitalares, em que são realizados os procedimentos cirúrgicos e de alta complexidade (cirurgia oncológica, radioterapia e quimioterapia). Destaca-se que os grandes centros de atenção oncológica se concentram nas regiões Sul e Sudeste (Brasil 2013, Oliveira, Melo, Pinheiro, Noronha \& Carvalho 2011).

Com relação aos hospitais, entre 2012 e 2017, observou-se que a quantidade no Brasil passou de 6,30 mil para 6,16 mil, respectivamente. Na análise por região do país, verificou-se que houve um aumento na quantidade destes hospitais no Norte e no Nordeste, enquanto no Sudeste, Sul e Centro-Oeste ocorreu um decréscimo, no período destacado.

De maneira similar, o número de leitos de internação do SUS passou de $326,03 \mathrm{mil} \mathrm{em} 2012$ para 303,18 mil em 2017, sendo que nesse último ano em questão, a região Sudeste concentrou a maior quantidade de leitos $(110,49$ mil), enquanto que o Centro-Oeste teve o menor número $(23,50 \mathrm{mil})$, conforme Tabela 2.

\section{Metodologia}

Para atender aos objetivos da pesquisa, é necessário adotar técnicas de análise espacial de dados, a saber, a Análise Exploratória de Dados Espaciais (AEDE) e duas abordagens de econometria espacial: modelos econométricos espaciais com enfoque global e o modelo GWR (Geographically Weighted Regression), que apresenta enfoque local. É importante notar que, para a estimação dos modelos econométricos espaciais, o logaritmo de todas as variáveis que o compõem foi tomado, linearizando os modelos na presente pesquisa.

A Análise Exploratória de Dados Espaciais - AEDE (conforme seção 4.2 deste estudo) antecede qualquer estudo espacial, pois permite verificar se as variáveis apresentam dependência espacial e auxilia na especificação dos modelos econométricos. Além disso, a adequada especificação de um modelo econométrico deve considerar todos os aspectos teóricos acerca do comportamento do setor, bem como o fenômeno específico a ser estudado.

Neste sentido, verifica-se que os estudos empíricos que tratam da economia da saúde têm utilizado com frequência modelos econométricos espaciais 
que incorporem os efeitos de transbordamento das variáveis envolvidas no fenômeno em estudo. Ou seja, considera-se que existe um efeito de uma região sobre as regiões vizinhas, em uma clara indicação que a estrutura de saúde é regionalizada, com pacientes de um município utilizando serviços de saúde de municípios vizinhos. Para incorporar esses efeitos são propostos os modelos econométricos espaciais globais (modelos SDM e SDEM), os quais são tratados na seção 4.3. Como inovação metodológica do presente estudo, são utilizados também métodos espaciais que capturem os efeitos locais (modelo SLX e, especialmente o modelo GWR) - seção 4.4.

No presente estudo foram usados os seguintes softwares: ArcGis 10.1, para construção dos mapas, GeoDaSpace 1.0, para estimação dos modelos econométricos espaciais globais e GWR 4.0, na estimativa do modelo GWR.

\subsection{Fonte e Descrição dos Dados}

Este estudo é do tipo descritivo, transversal e analítico em que se utilizou dados da morbidade hospitalar por câncer de mama disponíveis no Departamento de Informática do SUS - DATASUS (Brasil 2017b). A área de abrangência correspondeu às 558 microrregiões do Brasil e o período de análise foi o ano de 2013, dada a indisponibilidade de dados do PIB per capita municipal (variável explicativa) para os anos de 2014 a 2016, quando a coleta de dados foi feita (entre abril e junho de 2017).

Destaca-se que a morbidade hospitalar do SUS correspondeu ao número de internações hospitalares por câncer de mama em mulheres de 20 e 69 anos (a cada $100 \mathrm{mil}$ ), sendo a variável de interesse dessa pesquisa. Na coleta dos dados no site do DATASUS considerou-se os seguintes critérios: a) informações da morbidade no nível geral, por local de residência; b) Autorizações de Internações Hospitalares (AIH) aprovadas pelo SUS (correspondente a variável internação); c) microrregiões; d) ano de 2013; e) lista de morbidade CID-10 referente a neoplasia maligna da mama; f) faixa etária de 20 a 60 anos e g) sexo feminino.

Como possíveis fatores espaciais, o PIB per capita ( $\mathrm{R} \$$ mil) foi a variável escolhida para representar o aspecto econômico, enquanto os mamógrafos (a cada 100 mil mulheres), equipes de saúde (a cada 100 mil mulheres) e número de consultas da Atenção Básica (por mulher) representaram os determinantes de gestão em saúde. Cabe notar que todas as variáveis foram definidas em termos per capita, ou seja, foram divididas pela população da microrregião correspondente.

Na Tabela 3 estão apresentadas a descrição das variáveis explicativas usadas no presente estudo, bem como a fonte e descrição de cada uma. Além disso, tem-se o sinal esperado delas em relação à variável dependente (internações hospitalares por câncer de mama) com base na literatura científica levantada. Nesta linha, espera-se uma associação positiva entre o PIB per capita e o número destas internações, conforme evidenciado por Wünsch Filho \& Moncau (2002), Alvarez et al. (2009), Alvarez et al. (2009), Cunningham et al. (2010), Larsen et al. (2011), Oliveira, Melo, Pinheiro, Noronha \& Carvalho (2011), Chien et al. (2012), Palmer et al. (2012), Santos et al. (2013), Fei et al. (2015), Goldberg et al. (2015), Mohaghegh et al. (2015) e Zhou et al. (2015), em que as regiões com maior status socioeconômico apresentam alto risco de desenvolvimento da doença. 
Tabela 3: Variáveis explicativas da pesquisa, 2013

\begin{tabular}{|c|c|c|c|c|}
\hline Variáveis & Descrição & Fonte & $\mid$ Sinal Esperado $\mid$ & Literatura Científica \\
\hline \multicolumn{5}{|c|}{ Econômico } \\
\hline $\begin{array}{l}\text { PIB per ca- } \\
\text { pita }\end{array}$ & $\begin{array}{l}\text { Valor nominal do PIB per capita ( } \mathrm{R} \$ \text { mil), calculado } \\
\text { como sendo a soma do PIB municipal para cada mi- } \\
\text { crorregião, dividido pela população correspondente. }\end{array}$ & DATASUS & + & $\begin{array}{l}\text { Wünsch Filho \& Moncau (2002), } \\
\text { Alvarez et al. (2009), Alvarez et al. } \\
\text { (2009), Cunningham et al. (2010), } \\
\text { Larsen et al. (2011), Oliveira, Melo, } \\
\text { Pinheiro, Noronha \& Carvalho } \\
\text { (2011), Chien et al. (2012), Palmer } \\
\text { et al. (2012), Santos et al. (2013), } \\
\text { Fei et al. (2015), Goldberg et al. } \\
\text { (2015), Mohaghegh et al. (2015) e } \\
\text { Zhou et al. (2015) }\end{array}$ \\
\hline \multicolumn{5}{|c|}{ Gestão em saúde } \\
\hline Mamógrafos & $\begin{array}{l}\text { Quantidade de equipamentos instalados nos estabele- } \\
\text { cimentos de saúde contidos no Cadastro Nacional de } \\
\text { Estabelecimentos de Saúde (CNES). Os equipamentos } \\
\text { de diagnóstico por imagem considerados foram: Ma- } \\
\text { mógrafo com Comando Simples, Mamógrafo com Este- } \\
\text { reotaxia e Mamógrafo computadorizado. }\end{array}$ & DATASUS & + & $\begin{array}{l}\text { Lima-Costa \& Matos (2007), Oli- } \\
\text { veira, Pinheiro, Melo \& Carvalho } \\
\text { (2011), Santiago (2012) e Schneider } \\
\text { et al. (2014) }\end{array}$ \\
\hline $\begin{array}{l}\text { Equipes de } \\
\text { saúde }\end{array}$ & $\begin{array}{l}\text { Atendimento prestado na unidade básica de saúde ou } \\
\text { no domicílio, pelos profissionais (médicos, enfermei- } \\
\text { ros, auxiliares de enfermagem e agentes comunitários } \\
\text { de saúde) que compõem as Equipes de Saúde da Famí- } \\
\text { lia. Essas equipes são responsáveis pelo acompanha- } \\
\text { mento de um número definido de famílias, localiza- } \\
\text { das em uma área geográfica delimitada e priorizam as } \\
\text { ações de prevenção, promoção e recuperação da saúde. }\end{array}$ & DATASUS & - & $\begin{array}{l}\text { Parada et al. (2008), Jácome et al. } \\
\text { (2011) }\end{array}$ \\
\hline $\begin{array}{l}\text { Consultas } \\
\text { Atenção } \\
\text { Básica }\end{array}$ & $\begin{array}{l}\text { Quantidade de procedimentos aprovados para paga- } \\
\text { mento pelas Secretarias de Saúde. Os procedimentos } \\
\text { considerados foram as Consultas médicas em Atenção } \\
\text { Básica. }\end{array}$ & $\begin{array}{l}\text { CNES/ } \\
\text { DATASUS }\end{array}$ & + & $\begin{array}{l}\text { Lima-Costa \& Matos (2007), Bello } \\
\text { (2010), Oliveira, Pinheiro, Melo \& } \\
\text { Carvalho (2011), Schneider et al. } \\
\text { (2014) }\end{array}$ \\
\hline
\end{tabular}

Fonte: Elaboração própria (2018). 
De maneira similar, espera-se também relação positiva entre as variáveis mamógrafos, número de consultas da Atenção Básica e o número de internações hospitalares por câncer de mama nas microrregiões do Brasil. As duas variáveis correspondem ao acesso aos serviços de saúde, sendo que levam a um aumento do diagnóstico da doença, o que pode conduzir a um número alto dessas internações (Lima-Costa \& Matos 2007, Bello 2010, Oliveira, Pinheiro, Melo \& Carvalho 2011, Santiago 2012, Schneider et al. 2014). Por sua vez, espera-se associação negativa entre as equipes de saúde e a variável dependente, dado que ações de prevenção (realizadas primordialmente pelas equipes Saúde da Família) podem conduzir a uma redução nestas internações (Parada et al. 2008, Jácome et al. 2011).

\subsection{Análise Exploratória de Dados Espaciais (AEDE)}

A AEDE pode ser definida como o conjunto de técnicas que auxiliam na descrição e visualização da distribuição espacial dos dados, na identificação de localidades singulares (outliers espaciais) e/ou padrões de associação espacial (clusters espaciais) (Anselin 1999). Como elemento central à AEDE estão os efeitos decorrentes da dependência e da heterogeneidade espacial (Anselin 1988).

A dependência espacial (ou autocorrelação espacial) é o fenômeno em que a similaridade de valores de uma variável (correlação) é combinada com a similaridade da localização dessa mesma variável (Anselin 1999). Em outras palavras, a autocorrelação espacial ocorre quando o valor de uma variável de interesse $(y)$ em determinada região $i$ tende a estar associada ao valor dessa mesma informação nas áreas vizinhas $j$.

Já a heterogeneidade espacial é evidenciada quando ocorre instabilidade estrutural nas regiões, ou seja, quando se utiliza unidades espaciais muito distintas para explicar um mesmo fenômeno. Com isso, diferentes respostas são obtidas dependendo da localidade de cada variável (Almeida 2012). É importante salientar que a heterogeneidade espacial pode se refletir em termos de heterocedasticidade (Anselin 1988).

Para que se possa desenvolver a AEDE é necessária a determinação de uma matriz de ponderação espacial ou matriz de pesos espaciais $(W)$. Essa matriz é também ponto de partida para a especificação de modelos econométricos espaciais, por exemplo, modelos SAR, SEM, SDM, SDEM, SLX, entre outros (Anselin 1999).

De maneira geral, a matriz de pesos espaciais procura refletir o grau de interação entre duas ou mais regiões, podendo ser classificada de acordo com um critério geográfico (Almeida 2012). Este critério apoia-se na ideia de proximidade geográfica, sendo que o grau de interação entre duas ou mais áreas diminui conforme a distância entre as mesmas aumenta, ou seja, regiões mais próximas refletem maior grau de dependência espacial do que aquelas mais distantes entre si (Lesage 1998).

A proximidade geográfica é definida a partir da contiguidade, a qual abrange a vizinhança e a distância geográfica. Na matriz de vizinhança, duas regiões são consideradas vizinhas caso elas partilhem de uma fronteira física comum, sendo as convenções mais comuns as matrizes do tipo: rainha e torre. A desvantagem desse tipo de matriz reside no fato de que não é garantida uma conectividade balanceada, dado que podem existir regiões com grande área e 
com muitos vizinhos e aquelas com pouca área e poucos vizinhos (Almeida 2012).

Para resolver o problema das matrizes de vizinhança, pode-se adotar a matriz de distância geográfica ( $k$ vizinhos mais próximos), em que todas as unidades espaciais devem ter o mesmo número de vizinhos cada uma (Almeida 2012). Na presente pesquisa, as matrizes de pesos espaciais testadas foram 3 , 5, 7 e 9 vizinhos mais próximos (ou ainda, K3, K5, K7 e K9), justamente no intuito de combater o desbalanceamento de conectividade.

Após a determinação da matriz de pesos espaciais, pode-se desenvolver a análise da autocorrelação espacial global e local. Como estatística global, o índice $I$ de Moran é capaz de indicar não somente a existência de autocorrelação espacial (positiva ou negativa), mas também o grau de autocorrelação espacial entre regiões distintas (Getis 2009). Teoricamente, o I de Moran fornece a indicação do grau de associação linear entre os valores observados de uma variável de interesse $(z)$ e a média ponderada dos valores da vizinhança, ou das defasagens espaciais ( $W z)$ (Almeida et al. 2008).

Já a autocorrelação espacial local (ou ainda, padrões locais de autocorrelação espacial) pode ser analisada pelos chamados indicadores LISA (Local Indicator of Spatial Association) (Almeida 2012). Estes indicadores são capazes de determinar clusters espaciais significativos estatisticamente para cada observação, desde que o somatório dos indicadores locais, para todas as regiões, seja proporcional ao indicador global de autocorrelação espacial (Anselin 1995). Dessa forma, o LISA permite a decomposição de indicadores globais ( I de Moran) em indicadores locais ( $I$ de Moran local), ao computar um I $i$ para cada observação.

Os indicadores locais são melhor visualizados por meio do mapa de clusters LISA, o qual é construído combinando a informação do diagrama de dispersão de Moran e do mapa de significância das medidas de associação local $I$. De maneira similar ao diagrama de dispersão de Moran, este mapa ilustra a classificação em quatro categorias de associação espacial (Alto-Alto, Baixo-Alto, Baixo-Baixo, Alto-Baixo) estatisticamente significantes (Almeida 2012).

\subsection{Modelos Econométricos Espaciais}

O primeiro passo para a escolha do modelo econométrico espacial mais adequado é dado pela estimação do modelo clássico de regressão linear (MCRL) por Mínimos Quadrados Ordinários (MQO) (Florax et al. 2003), conforme equação 1:

$$
y=X \beta+\varepsilon
$$

em que $y$ é um vetor $n \times 1$ de observações sobre a variável dependente, $X$ é uma matriz $n \times k$ de observações sobre as variáveis explicativas exógenas com um vetor associado $k \times 1$ de coeficientes de regressão $\beta$ e $\varepsilon$ é um vetor $\mathrm{n} \times 1$ de termos de erro aleatório (Almeida 2012).

Na presente pesquisa, o modelo econométrico espacial proposto pode ser representado pela equação 2 : 


$$
\begin{array}{r}
\text { LN Internações hospitalares }=\beta_{1}+\beta_{2} \text { LN PIB per capita }+ \\
\beta_{3} L N \text { Mamógrafos }+\beta_{4} L N \text { Equipes de Saúde }+ \\
\beta_{5} \text { Consultas Atenção Básica }+\varepsilon
\end{array}
$$

É importante observar que, pela especificação da função do tipo log-log, os coeficientes na equação (2) têm uma interpretação de elasticidade constante. A elasticidade da variável de interesse ( $y=$ internações hospitalares) em relação a mudanças nas variáveis explicativas $(x)$ é dada por $\frac{\partial 1 n y}{\partial 1 n x}=\beta_{k}$. Dessa forma, um aumento de $10 \%$ na variável explicativa, eleva em uma dada variação percentual a variável de interesse (Greene 2012).

Após a especificação do modelo, testa-se a dependência espacial (Florax et al. 2003). Os testes para detecção de autocorrelação espacial utilizados são: o teste $I$ de Moran para análise de regressão linear; os testes Multiplicadores de Lagrange da defasagem (ML $\rho$ ) e do erro (ML $\lambda$ ) e o teste Anselin-Kelejian.

$\mathrm{Na}$ econometria espacial destacam-se três especificações de modelos: 1) Modelos de dependência espacial de alcance global; 2) Modelos de dependência espacial de alcance global e local e 3) Modelos de dependência espacial de alcance local (Almeida 2012).

O modelo de defasagem espacial ou modelo SAR (Spatial Autoregressive Model) e o modelo de erro autorregressivo espacial ou modelo SEM (Spatial Error Model) são as abordagens econométricas de dependência espacial de alcance global a serem especificadas. A formulação do modelo SAR é dada por:

$$
y=\rho W y+X \beta+\varepsilon
$$

em que $\rho$ é o coeficiente autorregressivo espacial, $W y$ é um vetor $n \times 1$ de defasagens espaciais para a variável dependente, $X$ é uma matriz de variáveis explicativas exógenas, $\beta$ são os coeficientes da regressão e o $\varepsilon$ é o erro aleatório (Almeida 2012). Já o modelo SEM é representado por:

$$
y=X \beta+\xi
$$

em que $X$ é uma matriz de variáveis explicativas exógenas, $\beta$ são os coeficientes da regressão e $\xi=\lambda W \xi+\varepsilon$, sendo $\lambda$ o parâmetro do erro autorregressivo espacial que acompanha a defasagem $W \xi$ somado ao erro (Almeida 2012).

Para a estimação dos modelos SAR e SEM, o método MQO pode não ser o mais apropriado (Almeida 2012). No caso do modelo SAR, dada a simultaneidade introduzida pela defasagem espacial, o coeficiente espacial $\rho$ será inconsistente se estimado por MQO. Já no modelo SEM, a inclusão de um termo de erro autorregressivo faz com que as estimativas por MQO sejam enviesadas (Rey \& Montouri 1999). Como alternativa, os modelos podem ser estimados utilizando o método de Máxima Verossimilhança (MV); no entanto, esse método tem como premissa a normalidade dos erros. Caso essa premissa não possa ser assegurada, outros métodos devem ser utilizados, como o Método 
das Variáveis Instrumentais (VI) ou Quase Máxima Verossimilhança (QMV) para o modelo SAR e o Método Generalizado dos Momentos (GMM) para o modelo SEM (Almeida 2012).

Já o modelo de Durbin espacial ou modelo SDM (Spatial Durbin Model) e o modelo de Durbin espacial do erro ou modelo SDEM (Spatial Durbin Error Model) são as abordagens econométricas de dependência espacial de alcance global e local a serem especificadas.

O modelo de Durbin espacial ou SDM incorpora a ideia de transbordamento tanto por meio da defasagem das variáveis independentes $(W X)$ quanto pelas variáveis dependentes defasadas espacialmente (Wy) (Almeida 2012). A formulação desse modelo é dada por:

$$
y=\lambda W y+X \beta-\lambda W X \beta+\varepsilon
$$

em que $\lambda W$ representam matrizes de pesos espaciais associadas a seus parâmetros $(y$ e $X), \beta$ são os coeficientes da regressão e o $\varepsilon$ é o erro aleatório (Almeida 2012).

Por sua vez, o modelo de Durbin espacial do erro ou modelo SDEM possui um alcance global, com o transbordamento sobre o termo de erro $(\xi)$ e um alcance local, ao incorporar componentes de transbordamento sobre as variáveis explicativas exógenas $(X)$ (Almeida 2012). Pode ser representado da seguinte maneira:

$$
y=X \beta+W X_{t}+\xi
$$

em que $X$ é uma matriz de variáveis explicativas exógenas, $\beta$ são os coeficientes da regressão, $W X \tau$ é um vetor $(k-1$ por 1$)$ de defasagens espaciais para as variáveis explicativas exógenas e $\xi=\lambda W \xi+\epsilon$, sendo $\lambda$ o parâmetro do erro autorregressivo espacial que acompanha a defasagem $W \xi$ mais o erro (Almeida 2012). Os modelos SDM e SDEM podem ser estimados por Máxima Verossimilhança (MV), caso haja normalidade dos erros. Caso essa premissa não possa ser assegurada, os modelos podem ser estimados pelo Método das Variáveis Instrumentais (VI) ou Quase Máxima Verossimilhança (QMV) e pelo Método Generalizado dos Momentos (GMM), respectivamente (Almeida 2012).

Por fim, o modelo regressivo cruzado espacial ou modelo SLX possui alcance local, dado que o impacto da dependência espacial pode ser observado para apenas algumas regiões da área de estudo (Almeida 2012). A especificação do modelo é dada por:

$$
y=X \beta+W X_{t}+\varepsilon
$$

em que $X$ é uma matriz de variáveis explicativas exógenas, $\beta$ são os coeficientes da regressão, $W X \tau$ é um vetor ( $k-1$ por 1$)$ de defasagens espaciais para as variáveis explicativas exógenas e $\varepsilon$ é o erro aleatório (Almeida 2012).

Cabe notar que o modelo SLX pode ser estimado por Mínimos Quadrados Ordinários (MQO) ou por Máxima Verossimilhança (MV) desde que as variáveis explicativas sejam exógenas (Rey \& Montouri 1999). 


\subsection{Modelo GWR}

$\mathrm{Na}$ análise espacial, Fotheringham et al. (2002) definem que parâmetros estimados globalmente podem não ser adequados para representar condições locais, por denotarem apenas respostas médias ou típicas. Assim, é recomendado, além da análise econométrica global, a realização de uma estimação local, especialmente na forma do modelo GWR (Geographically Weighted Regression).

O modelo GWR é um desenvolvimento do Modelo Clássico de Regressão Linear (MCRL), sendo especificado da seguinte forma:

$$
y_{i}=\beta_{o}\left(u_{i}, v_{i}\right)+\Sigma_{k} \beta_{k}\left(u_{i}, v_{i}\right) x_{i k}+\varepsilon_{i}
$$

em que $\left(u_{i}, v_{i}\right)$ representam as coordenadas do ponto $i$ no espaço e $\beta_{k}\left(u_{i}, v_{i}\right)$ o coeficiente local no ponto $i$. O termo de erro aleatório segue distribuição normal com média zero e variância constante (Almeida 2012).

No modelo GWR, em vez de os coeficientes serem estimados globalmente, estes são específicos para cada localidade $i$ (Brunsdon et al. 1996). Este modelo gera uma sequência de regressões lineares, estimadas para cada região, com o auxílio de subamostras de observações ponderadas pela distância geográfica (Almeida 2012).

A ponderação geográfica da estimação dos parâmetros do modelo GWR ocorre por meio da atribuição de pesos às observações individuais, a partir de um ponto focal (ponto de regressão ou de calibragem). Dessa forma, observações mais próximas apresentam um peso maior, enquanto aquelas mais distantes possuem um peso menor (Almeida 2012).

Destaca-se que a ponderação geográfica é feita pela função Kernel espacial, a qual utiliza a distância $\left(d_{i j}\right)$ entre dois pontos geográficos, representando duas regiões, e um parâmetro da largura da banda (b), para determinar um peso entre essas duas regiões, que é inversamente relacionado à distância geográfica $\left(w_{i j}\right)$ (Almeida 2012).

No que diz respeito à largura da banda da função Kernel, esta pode ser constante ou adaptativa (Almeida 2012). A vantagem desta última está em contornar o problema de eficiência do Kernel fixo, que pode ocorrer quando em algumas regiões, especialmente próximas da fronteira da área de estudo, a estimação dos coeficientes locais é feita com um número pequeno de observações. Isso só é possível dado que, no Kernel adapatativo, a largura da banda se expande em áreas com observações escassas e encolhe em áreas com alta densidade de dados (Chasco 2013).

A determinação da banda de Kernel é feita pela minimização do critério de informação Akaike (AIC). Assim, estimadas as regressões globais e locais, o critério AIC é utilizado para definir se há melhora no ajustamento do modelo com a regressão local (Fotheringham et al. 2002).

Frente a uma melhora no ajustamento do modelo com a regressão local, a diferença de critério é usada para detectar as variáveis do modelo que possuem variabilidade geográfica. Valores positivos da diferença de critério indicam que não há variabilidade geográfica nos termos locais. Já valores negativos e maiores ou iguais a 2 (em módulo) indicam a existência desta variabilidade (Nakaya 2016). 
Por fim, é importante notar que o modelo GWR pode ser especificado com dependência espacial. Dado que ainda pode haver autocorrelação remanescente nos resíduos do modelo estimado, a dependência espacial pode ser levada em conta dentro desse modelo (Almeida 2012).

\section{RESULTADOS E DISCUSSÃO}

Na presente seção estão apresentadas as análises descritiva e espacial dos dados, bem como os resultados dos modelos econométricos espaciais globais e do modelo GWR.

\subsection{Análise Descritiva e Espacial dos Dados}

Na Tabela 4 apresenta-se a estatística descritiva dos dados usados no artigo, correspondente às 558 microrregiões do Brasil em 2013. A média de internações hospitalares por câncer de mama foi de 18 a cada 100 mil mulheres, com coeficiente de variação de aproximadamente $68 \%$, indicando alta disparidade entre as áreas pesquisadas. Destaque para a microrregião de Muriaé (MG), em que o número de internações hospitalares foi o mais alto $(86,89 / 100 \mathrm{mil}$ mulheres). Além disso, 9 microrregiões não contabilizaram internações hospitalares por esta neoplasia no ano em questão, localizadas nos estados do Acre, Amapá e Amazonas, por isso o valor mínimo é nulo.

O valor médio do PIB per capita nas 558 microrregiões, em 2013, foi de R\$ 19,52 mil, sendo que o coeficiente de variação correspondeu a $83,61 \%$, o que demonstrou uma dispersão alta dessa variável entre estas áreas. As microrregiões de Itapemirim (ES) e Litoral Ocidental Maranhense (MA) apresentaram o maior e o menor valor dessa variável, correspondendo a $\mathrm{R} \$ 229,25$ mil e $R \$$ 4,27 mil, respectivamente (Tabela 4).

A média do número de mamógrafos foi de 1,10 a cada 100 mil mulheres no ano de 2013, com coeficiente de variação de $86,55 \%$. Destaque para as microrregiões de Sananduva (RS) que apresentou a maior quantidade $(6,41 / 100$ mil) e a Baixada Maranhense (MA) com um dos valores mais baixos $(0,17 / 100$ mil). Do total de áreas analisadas (558), 128 delas não contabilizaram o equipamento, localizadas principalmente nos estados do Amazonas, Ceará, Mato Grosso, Paraná e Rio Grande do Norte, o que está representado pelo valor zero na Tabela 4.

Em 2013, o número médio de equipes de saúde foi de 29,28 a cada $100 \mathrm{mil}$ mulheres, com coeficiente de variação de 36,39\%. A microrregião de Bertolínia (PI) apresentou o maior número de equipes de saúde $(67,42 / 100$ mil), já a microrregião de Campanha Central (RS) teve a menor quantidade, 3,71 a cada 100 mil (Tabela 4).

Por fim, a média do número de consultas da Atenção Básica foi de 1,40 por habitante, sendo que o coeficiente de variação foi de $80,10 \%$ (Tabela 4). O valor máximo dessas consultas foi de 13,34 por habitante (microrregião de Almeirim - PA) e o mínimo correspondeu a 0,30 por habitante (microrregião de Alto Pantanal - MT).

Em termos regionais, observa-se na Figura 1 a distribuição do número de internações hospitalares por câncer de mama nas microrregiões do Brasil, em 2013. As microrregiões situadas nas regiões Norte, Nordeste e parte do Centro-Oeste do Brasil apresentam baixo número de internações hospitalares, 
Tabela 4: Análise descritiva dos dados utilizados na pesquisa, Microrregiões do Brasil, 2013

\begin{tabular}{|c|c|c|c|c|c|}
\hline Variáveis & Média & $\begin{array}{l}\text { Desvio } \\
\text { padrão }\end{array}$ & $\begin{array}{l}\text { Coeficiente } \\
\text { de Variação } \\
(\%)\end{array}$ & Máximo & Mínimo \\
\hline $\begin{array}{l}\text { Internações hospitalares (a cada } 100 \mathrm{mil} \\
\text { mulheres) }\end{array}$ & 18,00 & 12,23 & 67,94 & 86,89 & 0,00 \\
\hline PIB per capita ( $\mathrm{R} \$$ mil $)$ & 19,52 & 16,32 & 83,61 & 229,25 & 4,27 \\
\hline Mamógrafos (a cada 100 mil mulheres) & 1,10 & 0,95 & 86,55 & 6,41 & 0,00 \\
\hline $\begin{array}{l}\text { Equipes de saúde (a cada } 100 \text { mil mulhe- } \\
\text { res) }\end{array}$ & 29,28 & 10,66 & 36,39 & 67,42 & 3,71 \\
\hline Consultas Atenção Básica (por mulher) & 1,40 & 1,12 & 80,10 & 13,34 & 0,30 \\
\hline
\end{tabular}

Fonte: Resultados da pesquisa (2018). Elaboração própria.

representados pelo cinza claro. Por outro lado, as microrregiões do Sul e Sudeste do país tem elevado número de internações hospitalares pela neoplasia (cinza escuro).

Dessa forma, pode-se notar certo padrão de distribuição espacial, o que indica que microrregiões com número de internações por câncer de mama semelhantes estão agrupadas em clusters espaciais. Essa associação espacial necessita de confirmação por meio de testes específicos, que serão mostrados nas seções seguintes.

É possível observar que o PIB per capita segue comportamento geográfico similar àquele observado na distribuição do número de internações hospitalares por câncer de mama. As microrregiões situadas em parte das regiões Norte e Nordeste apresentam PIB per capita mais baixo (em cinza claro), enquanto aquelas situadas no Sul, Sudeste e Centro-Oeste do país têm PIB per capita mais elevado (em cinza escuro) (Figura 2(a)).

A análise da distribuição geográfica do número de mamógrafos Figura (2(b)) revelou que as microrregiões da região Norte apresentam os piores resultados (em cinza claro). Por outro lado, as microrregiões situadas no Sul, Sudeste e Centro-Oeste do país têm um maior número de mamógrafos (em cinza escuro).

Por sua vez, na Figura 2(c) é possível notar que o número de equipes de saúde segue distribuição geográfica oposta àquela observada na distribuição do número de internações hospitalares por câncer de mama. De maneira geral, as microrregiões situadas no Sul e Sudeste do Brasil apresentam baixo número de equipes de saúde (em cinza claro), enquanto aquelas situadas no Norte, Nordeste e Centro-Oeste do país têm elevado número de equipes de saúde (em cinza escuro).

A análise da distribuição geográfica das consultas de Atenção Básica (Figura $2(\mathrm{~d})$ ) mostrou que as microrregiões da região Norte e parte do Nordeste apresentam os piores resultados (em cinza claro). Por outro lado, o número de consultas é mais elevado nas microrregiões situadas no Sul, Sudeste e CentroOeste do país (em cinza escuro). Conforme já destacado na metodologia da pesquisa, para estimar os modelos econométricos espaciais, foram usadas as variáveis dependente (internações por câncer de mama) e as explicativas (determinantes econômico e de gestão em saúde) em logaritmo natural (LN), conforme segue nas seções 5.2 até 5.4 . 
Figura 1: Distribuição do número de internações hospitalares por câncer de mama em mulheres, Microrregiões do Brasil, 2013

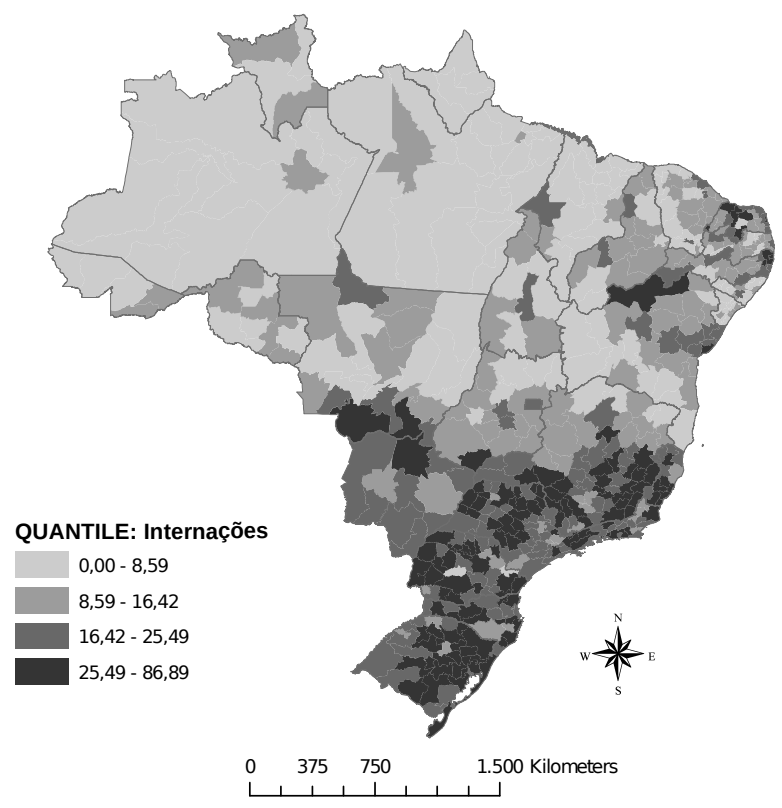

Fonte: Resultados da Pesquisa (2018). Elaboração própria.

\subsection{Análise da Autocorrelação Espacial Global e Local}

Os resultados da estatística $I$ de Moran para as internações hospitalares por câncer de mama (em logaritmo natural - LN) nas quatro diferentes matrizes de pesos espaciais testadas (K3, K5, K7 e K9) está apresentada na Tabela 5. Para todas as matrizes de pesos existe autocorrelação espacial positiva, dado que o coeficiente $I$ de Moran ficou acima do seu valor esperado $(-0,0018)$; além disso, estes valores foram significativos a $1 \%$.

A matriz que melhor representou a conexão entre as microrregiões, por apresentar o maior valor do I de Moran, foi a de 5 vizinhos. Dessa forma, em todas as análises e resultados apresentados posteriormente foi usada essa conexão espacial.

Nesta linha, tem-se o diagrama de dispersão de Moran para a variável internações hospitalares por câncer de mama apresentado na Figura 3(a). No eixo vertical e horizontal desse diagrama apresentam-se a defasagem espacial dessas internações (em LN) e a própria variável de interesse (em LN), respectivamente. Observa-se a existência de uma concentração de microrregiões nos 
Figura 2: Distribuição das variáveis explicativas - PIB per capita, Mamógrafos, Equipes de saúde e Consultas na Atenção Básica, Microrregiões do Brasil, 2013

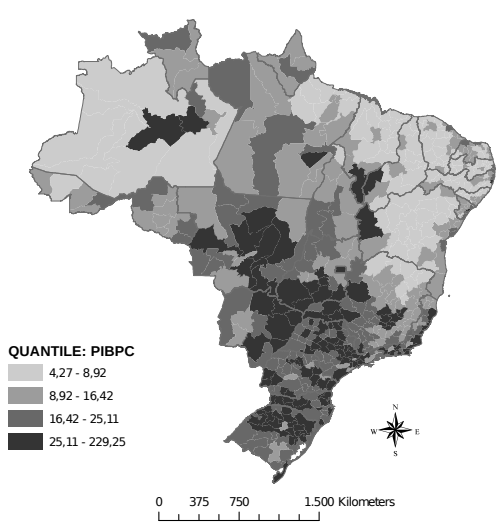

PIB per capita (R\$ mil)

(a)

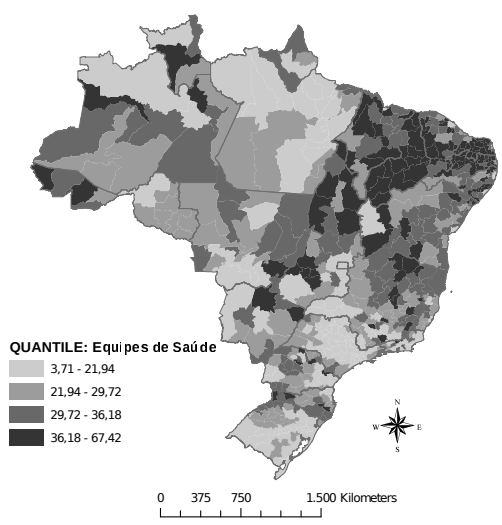

Equipes de Saúde

(c)

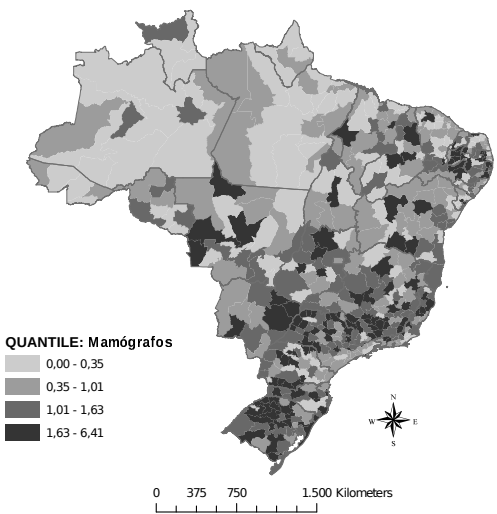

Mamógrafos

(b)

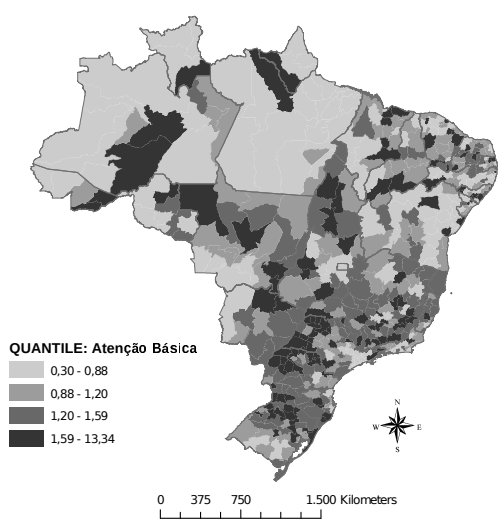

Consultas Atenção Básica

(d)

Fonte: Resultados da Pesquisa (2018). Elaboração própria. 
Tabela 5: Autocorrelação espacial global - Internações hospitalares por câncer de mama em mulheres, em logaritmo natural - LN, Microrregiões do Brasil, 2013

\begin{tabular}{c|c|c}
\hline Matrizes de contiguidade & I de Moran & P-Valor \\
\hline K3 & 0,6069 & $0,001^{*}$ \\
K5 & $\mathbf{0 , 6 3 3 7}$ & $\mathbf{0 , 0 0 1}$ \\
K7 & 0,6216 & $0,001^{*}$ \\
K9 & 0,6182 & $0,001^{*}$ \\
\hline
\end{tabular}

Fonte: Resultados da Pesquisa (2018). Elaboração própria.

Nota: *Significativo a $1 \%$.

quadrantes Alto-Alto (primeiro quadrante) e Baixo-Baixo (terceiro quadrante). Logo, em 2013, as microrregiões que demonstraram alto (baixo) número de internações por esta neoplasia estavam rodeadas por áreas que também apresentavam elevada (baixa) morbidade por este tipo de enfermidade crônica.

Na Figura 3(b), observa-se em cinza mais escuro as microrregiões AltoAlto (formação de aglomerações com alto número de internações por câncer de mama rodeadas por regiões com elevada quantidade dessa variável) no Sudeste e no Centro-Sul do Brasil, principalmente em São Paulo, Minas Gerais, Espírito Santo, Mato Grosso do Sul, Paraná, Santa Catarina e Rio Grande do Sul.

Figura 3: Diagrama de dispersão de Moran (a) e Mapa de Cluster LISA (b) das internações hospitalares por câncer de mama em mulheres, em logaritmo natural - LN, Microrregiões do Brasil, 2013

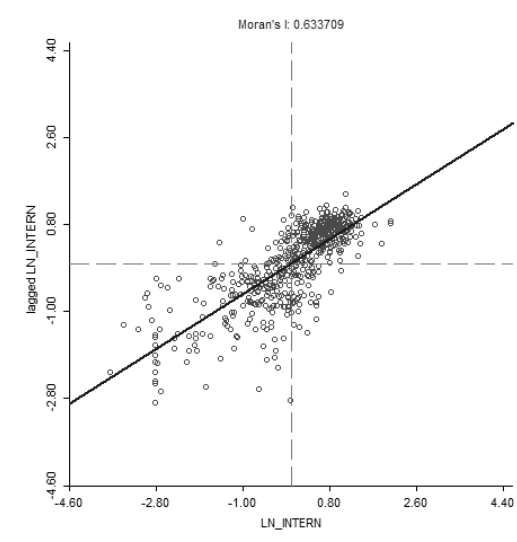

(a)

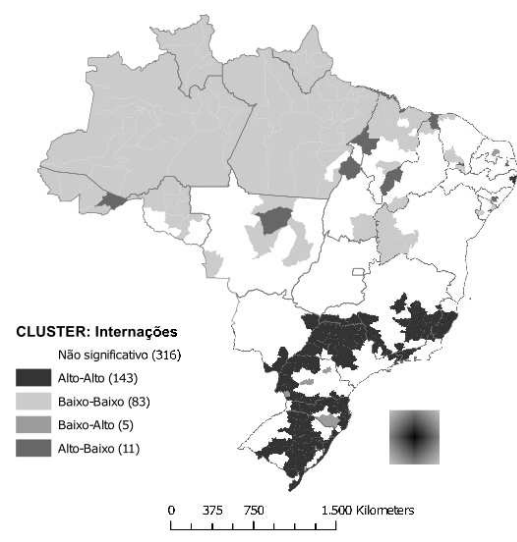

(b)

Fonte: Resultados da Pesquisa (2018). Elaboração própria.

Nota: Mapa com 999 permutações e com nível de significância de 5\%.

Por sua vez, as áreas em cinza mais claro corresponderam às microrregiões Baixo-Baixo, situados em grande parte no Norte e Nordeste do Brasil. Os estados do Acre, Amapá, Amazonas, Pará, Rondônia, Roraima, Tocantins, Bahia e Maranhão concentram essas aglomerações. É possível visualizar ainda a formação de algumas aglomerações Baixo-Alto (regiões com baixo número de internações hospitalares por câncer de mama rodeados por áreas com ele- 
vada quantidade dessa variável), realçados em cinza claro e Alto-Baixo (clusters com alto número de internações por essa doença com vizinhos com baixa quantidade dessa variável) denotados em cinza escuro, aparecendo dispersos pelo mapa (Figura 3).

\subsection{Resultados dos Modelos Econométricos Espaciais}

O primeiro passo para a escolha do modelo econométrico espacial mais adequado, conforme já destacado na metodologia, é dado pela estimação do modelo por Mínimos Quadrados Ordinários (MQO). Na Tabela 6 apresentam-se os coeficientes da regressão, bem como os resultados dos testes de diagnóstico da estimação por MQO. Os coeficientes estimados foram todos estatisticamente significativos, explicando $31,05 \%$ da regressão. O teste de multicolinearidade indica que o modelo não apresenta problemas de multicolinearidade e o teste Jarque-Bera aponta que os erros não são normais. Já os testes de Breusch-Pagan e Koenker-Bassett indicam a presença de heterocedasticidade (ou seja, que o erro aleatório não tem variância constante).

Tabela 6: Diagnóstico da regressão estimada por MQO - Variável dependente: Internações hospitalares por câncer de mama em mulheres, em logaritmo natural - LN, Microrregiões do Brasil, 2013

\begin{tabular}{lc}
\hline Variáveis & Coeficientes \\
\hline Constante & $1,8668^{*}$ \\
PIB per capita & $0,5072^{*}$ \\
Mamógrafos & $0,3680^{*}$ \\
Equipes de Saúde & $-0,2384^{* *}$ \\
Consultas Atenção Básica & $0,3034^{*}$ \\
\hline \multicolumn{1}{c}{ Diagnóstico da regressão } \\
\hline $\mathrm{R}^{2}$ & 0,3105 \\
Multicolinearidade & 31,00 \\
Jarque-Bera & $212,46^{*}$ \\
Breusch-Pagan & $33,08^{*}$ \\
Koenker-Bassett & $17,00^{*}$ \\
\hline \multicolumn{1}{c}{ Diagnóstico para autocorrelação espacial } \\
\hline$I$ de Moran (erro) & $0,4446^{*}$ \\
ML $\rho$ (defasagem) & $331,43^{*}$ \\
ML $\rho$ (defasagem) & $37,44^{*}$ \\
ML $\lambda$ (erro) & $303,68^{*}$ \\
ML* $\lambda$ (erro) & $9,69^{*}$ \\
\hline Fonte: Resultados da Pesquisa (2018). Elaboração \\
própria. \\
Nota: ${ }^{*}$ Significativo a 1\%. ${ }^{*}$ Significativo a $5 \% .{ }^{* * *}$ \\
Significativo a 10\%.
\end{tabular}

Conforme Tabela 6, os testes para detecção de autocorrelação espacial apresentam $I$ de Moran difuso de 0,44 e significativo a $1 \%$, enquanto os testes focados do tipo Multiplicadores de Lagrange (ML $\rho$ e ML $\lambda$ ) também se mostram estatisticamente significativos a $1 \%$. Nesta linha, é necessário verificar 
as versões robustas dos testes $\left(\mathrm{ML}^{\star} \rho\right.$ e $\left.\mathrm{ML}^{\star} \lambda\right)$ para a escolha do modelo econométrico espacial mais adequado.

Na Tabela 6 o valor referente ao ML robusto da defasagem $\left(\mathrm{ML}^{\star} \rho=37,44\right)$ foi superior ao $\mathrm{ML}$ robusto de erro $\left(\mathrm{ML}^{*} \lambda=9,69\right)$, indicando que o modelo de defasagem espacial (SAR) pode ser o mais adequado para verificar a relação entre o número de internações hospitalares por câncer de mama e as variáveis explicativas nas microrregiões do Brasil em 2013. Para efeito de comparação, o modelo de erro autorregressivo espacial (SEM) também foi estimado.

Na Tabela 7 estão apresentados os resultados dos modelos globais estimados SAR e SEM. Em virtude da não normalidade observada nos erros, o método de Máxima Verossimilhança (MV) não é o mais adequado. Logo, o método de Mínimos Quadrados em 2 Estágios (MQ2E) foi usado no modelo SAR, enquanto o método Generalizado dos Momentos (GMM) foi utilizado no modelo SEM.

Destaca-se que a partir do teste Anselin-Kelejian (que tem como hipótese nula a não autocorrelação espacial nos resíduos do modelo) evidenciou-se que o modelo SAR não incorporou corretamente a autocorrelação espacial dos erros, pois rejeita a hipótese nula a nível de $1 \%$ de significância. Assim, a análise desse modelo não é feita no presente estudo (Tabela 7).

Tabela 7: Resultados dos modelos econométricos espaciais SAR e SEM, em logaritmo natural - LN, Microrregiões do Brasil, 2013

\begin{tabular}{l|c|c}
\hline Variáveis & $\begin{array}{c}\text { Coeficientes modelo } \\
\text { SAR }\end{array}$ & $\begin{array}{c}\text { Coeficientes modelo } \\
\text { SEM }\end{array}$ \\
\hline Constante & 0,2529 & $2,3585^{*}$ \\
PIB per capita & $0,1919^{*}$ & $0,4067^{*}$ \\
Mamógrafos & $0,1260^{* *}$ & $0,1055^{* *}$ \\
Equipes de Saúde & $-0,0750$ & $-0,2815^{*}$ \\
Consultas Atenção Básica & 0,0119 & $0,1063^{* *}$ \\
$\rho$ (defasagem) & $0,7848^{*}$ & - \\
(erro) & - & $0,7143^{*}$ \\
\hline Anselin-Kelejian & $7,46^{*}$ & - \\
\hline Fonte: Resultados da Pesquisa (2018). Elaboração própria. \\
Nota: ${ }^{*}$ Significativo a 1\%. ${ }^{* *}$ Significativo a 5\%. ${ }^{* * *}$ Significativo a $10 \%$.
\end{tabular}

De acordo com os resultados do modelo SEM (Tabela 7), existe uma relação espacial global positiva entre internações hospitalares por câncer de mama no Brasil, em 2013, e os determinantes PIB per capita, mamógrafos e consultas da Atenção Básica, sendo que seus coeficientes foram significativos. Conforme destacado na metodologia, a intepretação destes coeficientes é feita da seguinte forma: um aumento de $10 \%$ nas variáveis PIB per capita, mamógrafos e consultas da Atenção Básica elevam, respectivamente, em 4,07\%, 1,05\% e 1,06\% estas internações.

Por sua vez, a partir do sinal negativo do coeficiente das equipes de saúde (Tabela 7), verifica-se que uma elevação de $10 \%$ nesta variável, reduz as internações hospitalares no SUS por essa enfermidade em $2,81 \%$. Destaca-se que o coeficiente do erro autorregressivo espacial $(\lambda)$ se mostrou significativo a $1 \%$ e positivo $(0,71)$, indicando que os efeitos não captados pelo modelo apresentam autocorrelação espacial positiva. Dessa forma, altos (baixos) valores 
desses efeitos não modelados provocam choques de altos (baixos) valores na vizinhança.

Dado que as características das microrregiões vizinhas podem ser importantes na determinação dos condicionantes das internações hospitalares por câncer de mama em determinada microrregião, incorpora-se as defasagens espaciais das variáveis explicativas nos modelos SDM, SDEM e SLX, apresentados na Tabela 8. O método de Mínimos Quadrados em 2 Estágios (MQ2E) foi utilizado no modelo SDM, enquanto o método Generalizado dos Momentos (GMM) foi utilizado para estimação do modelo SDEM, dada a não normalidade dos erros. Já o modelo SLX foi estimado por Mínimos Quadrados Ordinários (MQO).

A partir do teste Anselin-Kelejian notou-se que o modelo SDM não incorporou corretamente a autocorrelação espacial dos erros. Dessa forma, a análise do modelo não é feita, conforme informações apresentadas na Tabela 8.

Tabela 8: Resultados dos modelos econométricos espaciais SDM, SDEM e SLX, em logaritmo natural - LN, Microrregiões do Brasil, 2013

\begin{tabular}{l|c|c|c}
\hline Variáveis & $\begin{array}{c}\text { Coeficientes } \\
\text { modelo SDM }\end{array}$ & $\begin{array}{c}\text { Coeficientes } \\
\text { modelo SDEM }\end{array}$ & $\begin{array}{c}\text { Coeficientes } \\
\text { modelo SLX }\end{array}$ \\
\hline Constante & 0,5038 & $2,2638^{* *}$ & $2,6725^{*}$ \\
PIB per capita & $0,3375^{*}$ & $0,3578^{*}$ & $0,3245^{*}$ \\
Mamógrafos & 0,0753 & $0,1763^{*}$ & $0,1821^{*}$ \\
Equipes de Saúde & $-0,2890^{*}$ & $-0,3095^{*}$ & $-0,3569^{*}$ \\
Consultas Atenção Básica & 0,0498 & $0,1194^{* *}$ & $0,1503^{* *}$ \\
W_PIB per capita & $-0,3120^{*}$ & 0,0207 & 0,0066 \\
W_Mamógrafos & $0,2048^{* * *}$ & $0,5626^{*}$ & $0,7819^{*}$ \\
W_Equipes de Saúde & $0,2261^{* * *}$ & 0,0370 & $-0,0292$ \\
W_Consultas Atenção Básica & 0,0040 & 0,2514 & $0,4783^{*}$ \\
$\rho$ (defasagem) & $0,8370^{*}$ & - & - \\
(erro) & - & $0,6610^{*}$ & - \\
\hline Anselin-Kelejian & $12,57^{*}$ & - & - \\
\hline Fonte: Resultados da Pesquisa (2018). Elaboração própria. & \\
Nota: ${ }^{*}$ Significativo a 1\%. ${ }^{* *}$ Significativo a 5\%. ${ }^{* * *}$ Significativo a $10 \%$.
\end{tabular}

No modelo SDEM, a defasagem da variável mamógrafos (W_mamógrafos) foi a única estatisticamente significativa a $1 \%$. Assim, um aumento de $10 \%$ na quantidade de mamógrafos nas microrregiões vizinhas ocasiona um crescimento de 5,63\% no número de internações hospitalares nas microrregiões em análise. Já no modelo SLX, a defasagem das variáveis mamógrafos (W_Mamógrafos) e consultas de Atenção Básica (W_Consultas Atenção Básica) se mostraram estatisticamente significativas a $1 \%$. Dessa forma, um aumento de $10 \%$ dessas duas variáveis nas microrregiões vizinhas ocasiona uma expansão de $7,82 \%$ e $4,78 \%$, respectivamente, nas internações hospitalares por essa doença nas microrregiões analisadas.

\subsection{Resultados do Modelo GWR}

Na Tabela 9 estão demonstrados os resultados das estimações globais e locais para as especificações do modelo GWR sem o componente espacial e SEM, SDEM e SLX. Para todos os modelos estimados, ao se comparar o critério de informação AIC, encontra-se um valor mais baixo para o modelo local, o que 
Tabela 9: Resultados do modelo GWR, em logaritmo natural - LN, Microrregiões do Brasil, 2013

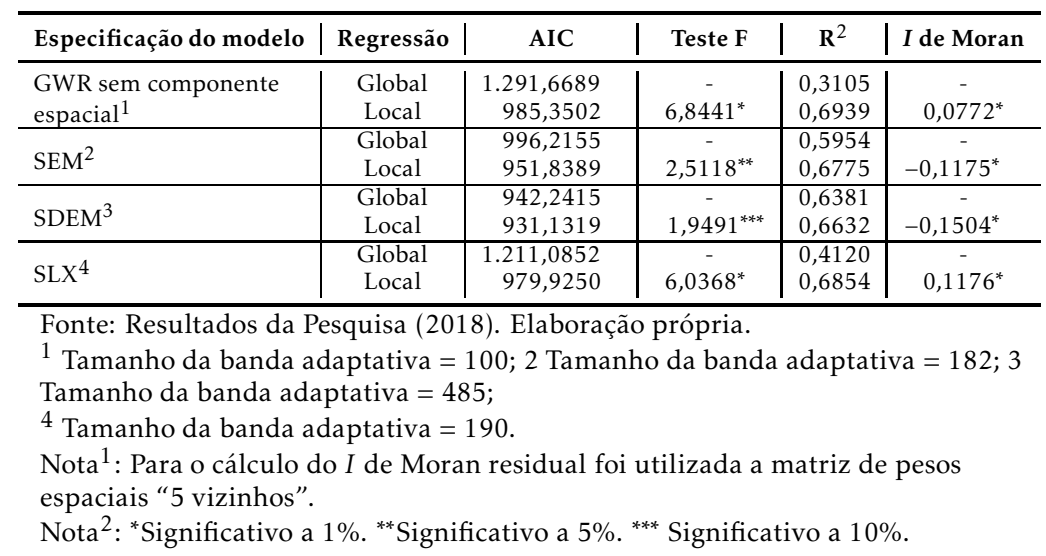

sugere que a estimação desse último é mais ajustada. O mesmo pode ser inferido ao se comparar o $\mathrm{R}^{2}$ (coeficiente de determinação) dos modelos global e local, apresentando maior valor no último.

Por sua vez, o teste F indica que o modelo GWR apresentou melhora sobre o modelo global, a um nível de significância de 5\% no modelo SEM, de $10 \%$ no modelo SDEM e a um nível de significância de $1 \%$ no modelo SLX. Ainda há indícios de autocorrelação nos resíduos, dado a significância do I de Moran.

Nas Tabelas 10 e 11 apresentam-se os coeficientes locais (quartis) e a diferença de critério, procedimento que detecta as variáveis que possuem variabilidade geográfica, para os modelos SEM e SLX, respectivamente. A partir dos resultados destas estimações, foi possível apresentar o impacto dos coeficientes locais das microrregiões para as variáveis que apresentaram variabilidade geográfica, conforme exposto nas Figuras 4 (mapas a e b) e 5 (mapas a, b, c e d), nesta ordem. Nestas figuras as microrregiões que não foram estatisticamente significativos a $5 \%$ estão na cor branca. Já aquelas que demonstraram os coeficientes com os sinais esperados e significativos estão em cinza escuro, aumentando a tonalidade quanto maior se deu seu impacto, enquanto as áreas que não apresentaram os sinais esperados estão em cinza claro.

Conforme os resultados do modelo SEM (Tabela 10), as variáveis com coeficientes que têm variabilidade geográfica são o PIB per capita (PIBPC) e as equipes de saúde. O efeito espacial local do PIB per capita Figura 4(a) é mais alto nas microrregiões pertencentes ao Norte, Nordeste e Sul do Brasil, o que significa que um crescimento da renda per capita nessas regiões teria um forte efeito local no número de internações hospitalares por câncer de mama.

Com relação às equipes de saúde (Figura $4 \mathrm{~b}$ ), o efeito espacial é maior nas microrregiões pertencentes ao Norte do país (com destaque para o Acre, Amazonas e Rondônia), ao Centro-Oeste (estados de Goiás, Mato Grosso e Mato Grosso do Sul) e Sudeste (especialmente, em Minas Gerais e Espírito Santo). Nestas regiões, um aumento do número de equipes de saúde teria influência negativa sobre o número de internações hospitalares por câncer de mama. Em sentido contrário ao sinal esperado, nas microrregiões pertencentes ao Pará e Tocantins (Norte), bem como ao Ceará, Maranhão e Piauí (Nordeste), destacados em cinza claro, uma expansão do número de equipes de saúde teria influência positiva sobre a morbidade hospitalar desta neoplasia. 
Tabela 10: Coeficientes locais e diferença de critério do modelo SEM estimado por GWR, em logaritmo natural - LN

\begin{tabular}{l|c|c|c|c}
\hline Variáveis & $\begin{array}{c}\text { Quartil } \\
\text { Inferior }\end{array}$ & Médio & $\begin{array}{c}\text { Quartil } \\
\text { Superior }\end{array}$ & $\begin{array}{c}\text { Diferença de } \\
\text { Critério }\end{array}$ \\
\hline Intercepto & 2,5862 & 2,6582 & 2,8836 & $-30,5269$ \\
PIB per capita & $\mathbf{0 , 1 2 7 5}$ & $\mathbf{0 , 3 0 5 4}$ & $\mathbf{0 , 3 7 0 4}$ & $-2 \mathbf{1 , 5 2 9 0}$ \\
Mamógrafos & 0,0218 & 0,0575 & 0,0860 & 9,1742 \\
Equipes de saúde & $\mathbf{- 0 , 1 0 7 9}$ & $-\mathbf{0 , 0 4 2 3}$ & $\mathbf{0 , 0 1 1 7}$ & $\mathbf{- 1 0 , 1 3 8 2}$ \\
Consultas Atenção Básica & 0,0111 & 0,0350 & 0,0577 & 10,4269 \\
$\lambda$ (erro) & 0,2674 & 0,3489 & 0,4050 & 3,9763 \\
\hline
\end{tabular}

Fonte: Resultados da Pesquisa (2018). Elaboração própria.

Nota: Os coeficientes que possuem variabilidade geográfica estão destacados em negrito.

Observa-se na Figura 4(b) que na maior parte do Brasil (área em branco) o efeito local das equipes de saúde sobre a diminuição das internações por câncer de mama não é significativo.

Figura 4: Impacto dos coeficientes locais significativos, modelo SEM, em logaritmo natural - LN, Microrregiões do Brasil, 2013

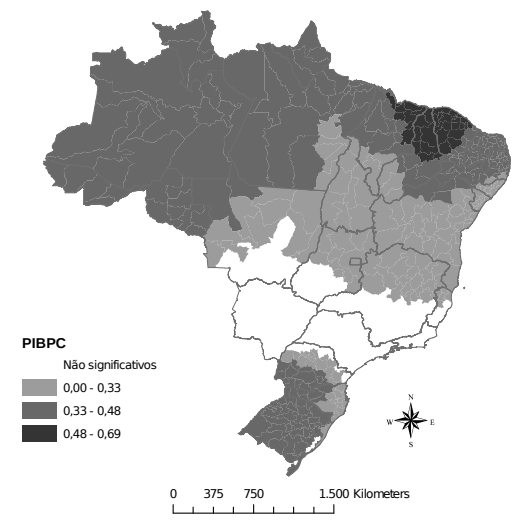

Efeito local: PIBPC

(a)

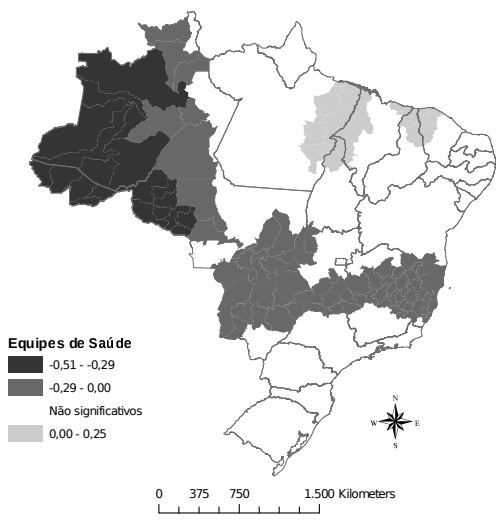

Efeito local: Equipes de Saúde

(b)

Fonte: Resultados da Pesquisa (2018). Elaboração própria.

Nota: Considerando Teste $t_{c}=1,96$, ao nível de significância de $5 \%$.

Já no modelo SLX (Tabela 11), as variáveis com coeficientes que têm variabilidade geográfica são o PIB per capita, o PIB per capita defasado espacialmente, as equipes de saúde defasadas espacialmente e as consultas de Atenção Básica defasadas no espaço. Observa-se na Figura 5(a) que o efeito espacial do PIB per capita no modelo SLX é maior nas microrregiões pertencentes ao Norte, Nordeste e Sul do Brasil, assim como observado no modelo SEM.

De maneira similar, o PIB per capita defasado espacialmente Figura 5(b) 
Tabela 11: Coeficientes locais e diferença de critério do modelo SLX estimado por GWR, em logaritmo natural - LN

\begin{tabular}{l|r|r|r|r}
\hline Variáveis & $\begin{array}{r}\text { Quartil } \\
\text { Inferior }\end{array}$ & Médio & $\begin{array}{c}\text { Quartil } \\
\text { Superior }\end{array}$ & $\begin{array}{c}\text { Diferença de } \\
\text { Critério }\end{array}$ \\
\hline Intercepto & 2,3869 & 2,7370 & 3,1115 & $-76,0998$ \\
PIB per capita & $\mathbf{0 , 0 4 0 1}$ & $\mathbf{0 , 2 5 8 2}$ & $\mathbf{0 , 3 3 7 9}$ & $-\mathbf{1 0 , 2 5 8 7}$ \\
Mamógrafos & 0,0039 & 0,0404 & 0,0724 & 7,9701 \\
Equipes de saúde & $-0,1079$ & $-0,0642$ & $-0,0453$ & $-1,6662$ \\
Consultas Atenção Básica & $-0,0094$ & 0,0144 & 0,0390 & 9,5958 \\
W_PIB per capita & $-\mathbf{0 , 2 1 4 8}$ & $-\mathbf{0 , 0 9 2 8}$ & $\mathbf{0 , 1 9 0 0}$ & $-2,6015$ \\
W_Mamógrafos & 0,0286 & 0,1065 & 0,1659 & 2,4056 \\
W_Equipes de Saúde & $-\mathbf{0 , 0 2 7 0}$ & $\mathbf{0 , 0 4 6 6}$ & $\mathbf{0 , 3 6 5 7}$ & $-\mathbf{7 , 0 6 5 8}$ \\
W_Consultas Atenção Básica & $\mathbf{- 0 , 0 6 9 3}$ & $\mathbf{- 0 , 0 0 8 1}$ & $\mathbf{0 , 0 7 1 6}$ & $-\mathbf{2 1 , 4 8 5 8}$ \\
\hline
\end{tabular}

Fonte: Resultados da Pesquisa (2018). Elaboração própria.

Nota: Os coeficientes que possuem variabilidade geográfica estão destacados em negrito.

demonstrou efeito mais alto nas microrregiões do Norte do país, com destaque para o Acre, Amazonas e Rondônia. Assim, um crescimento no PIB per capita das microrregiões vizinhas pode exercer influência positiva sobre as internações hospitalares por câncer de mama da microrregião em questão. Por sua vez, diferente do sinal esperado, nas microrregiões pertencentes aos estados de Tocantins (Norte), Bahia (Nordeste), parte do Mato Grosso do Sul (CentroOeste), São Paulo (Sudeste) e Paraná (Sul), um aumento no PIB per capita das microrregiões vizinhas exerce impacto negativo sobre as internações hospitalares por esta doença sobre a microrregião em análise Figura 5(b).

Com relação às equipes de saúde defasadas Figura 5(c), o efeito espacial é maior na região central do Brasil, com destaque para as microrregiões pertencentes aos estados de Goiás e Mato Grosso (Centro-Oeste) e na Bahia (Nordeste). Dessa forma, um aumento das equipes de saúde das microrregiões vizinhas pode levar a uma diminuição das internações hospitalares por câncer de mama na microrregião em análise. Por outro lado, nas microrregiões pertencentes ao Norte e Nordeste do país (em cinza claro no mapa), um crescimento das equipes de saúde das microrregiões vizinhas pode levar a uma expansão da morbidade por essa doença na microrregião em questão, não estando em consonância com o sinal esperado.

Já o efeito espacial das consultas de Atenção Básica defasada Figura 5(d) é maior nas microrregiões centrais do Brasil com destaque para os estados de Goiás, Mato Grosso e Mato Grosso do Sul (Centro-Oeste), Tocantins (Norte), Bahia (Nordeste) e Minas Gerais (Sudeste). Nestas áreas, uma expansão do número de consultas de Atenção Básica nas microrregiões vizinhas pode levar a um aumento do número de internações hospitalares por câncer de mama na microrregião em questão. Diferente do sinal esperado, no Nordeste do país (em cinza claro no mapa), uma elevação na quantidade de consultas da Atenção Básica nas microrregiões vizinhas tende a reduzir as internações na microrregião em destaque.

É importante observar também que a cor branca nos mapas (b), (c) e (d) da Figura 5 abrange grande parte dos estados brasileiros. Isso indica que o efeito local da vizinhança de cada determinante sobre as internações por câncer de mama foi não significativo. 
Figura 5: Impacto dos coeficientes locais significativos, modelo SLX, em logaritmo natural - LN, Microrregiões do Brasil, 2013

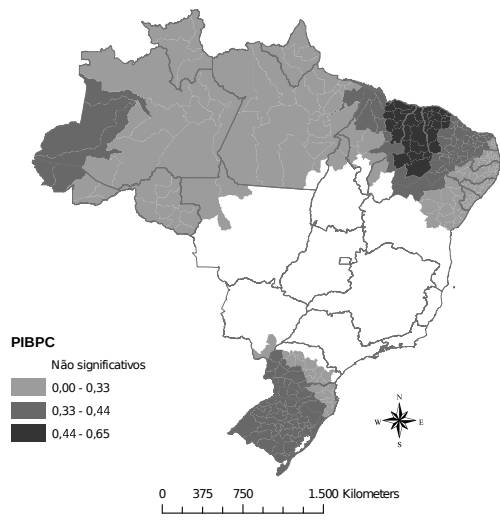

Efeito local: PIBPC

(a)

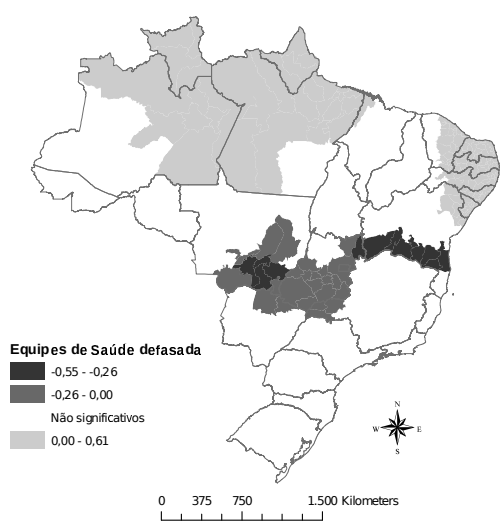

Efeito local: Equipes de Saúde defasada (c)

Fonte: Resultados da Pesquisa (2018). Elaboração própria.

Nota: Considerando Teste $t_{c}=1,96$, ao nível de significância de $5 \%$.

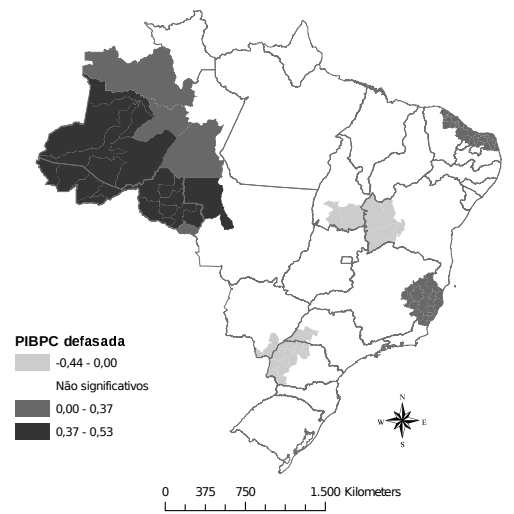

Efeito local: PIBPC defasada (b)

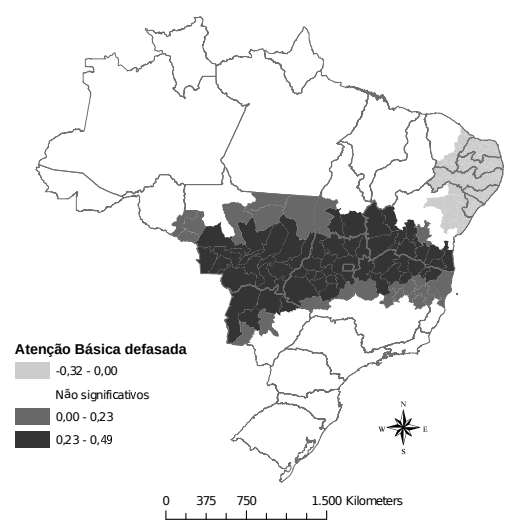

Efeito local: Consultas Atenção Básica defasada (d) 
A partir dos resultados apresentados na presente pesquisa, verificou-se que o fator econômico (PIB per capita) mostrou associação positiva com o número de internações hospitalares por câncer de mama, em 2013, apresentando dependência espacial tanto no modelo estimado globalmente, abordando características gerais, quanto localmente, ao serem consideradas as condições locais dessas regiões (modelo GWR). Lima-Costa \& Matos (2007), Oliveira, Pinheiro, Melo \& Carvalho (2011), Santiago (2012) e Schneider et al. (2014) destacam que, no Brasil, mulheres de classes socioeconômicas mais elevadas tendem a realizar exames de mamografia com maior regularidade, o que pode levar a um aumento do número de diagnósticos de câncer de mama. Esta expansão do diagnóstico, por sua vez, pode incorrer em uma alta morbidade hospitalar pela doença.

Neste estudo, a relação entre mamógrafos e internações por câncer de mama se mostrou positiva, sendo que a quantidade de mamógrafos de regiões vizinhas também exerceu influência sobre estas morbidades no ano de análise (2013). As regiões Sul e Sudeste apresentaram o mais alto número de mamógrafos, concentrando, consequentemente, o maior número de internações hospitalares por esta neoplasia.

Em sentido contrário, Lima-Costa \& Matos (2007), Oliveira, Pinheiro, Melo \& Carvalho (2011) e Azevedo et al. (2014) encontraram que as regiões menos desenvolvidas economicamente, como no caso do Norte, Nordeste e CentroOeste, apresentam acesso limitado à mamografia, o que implica em um menor número de diagnósticos da neoplasia. Dessa forma, as internações hospitalares por câncer de mama podem não chegar a ocorrer, o que também pode ser observado nessa pesquisa.

Com relação às consultas da Atenção Básica do SUS, mulheres de áreas mais desenvolvidas economicamente (como no caso das regiões Sul e Sudeste) tendem a ir a consultas médicas com mais frequência, o que leva a uma maior quantidade de pedidos de mamografia. Esse fato está associado a um alto número de diagnósticos da doença, e consequentemente, de internações hospitalares (Lima-Costa \& Matos 2007, Bello 2010, Oliveira, Pinheiro, Melo \& Carvalho 2011, Schneider et al. 2014). Além disso, a concentração de profissionais de saúde no Sul e Sudeste do país contribui com a identificação desta enfermidade (Scheffer 2015). Os achados da presente pesquisa estão em consonância com os estudos destacados, pois a relação entre consultas de Atenção Básica e internações hospitalares se mostrou positiva, sendo que a dependência espacial pode ser observada tanto globalmente quanto localmente, para o ano de 2013.

Por sua vez, a prevenção ao câncer de mama mostra relação negativa com o número de casos da doença. Esta envolve tanto a redução da exposição a agentes cancerígenos relacionados a fatores ambientais e comportamentais quanto a ações de detecção precoce, ocorrendo sobremaneira na Atenção Básica do SUS, que envolve as equipes Saúde da Família (BRASIL 2013). Dentre os principais atributos desses profissionais destacam-se a realização de consultas, exame clínico das mamas, avaliação de sinais e sintomas relacionados à doença, solicitação e avaliação de exames, encaminhamento e acompanhamento nos serviços de referência para diagnóstico e/ou tratamento, realização de cuidados paliativos e participação das atividades de educação permanente (Rodrigues et al. 2012, Gutiérrez 2013, Parada et al. 2008).

Salienta-se que as ações no âmbito da Saúde da Família facilitam o conhecimento prévio por parte das mulheres na detecção precoce do câncer de mama, 
proporcionam maior autonomia para o autocuidado e desenvolvem o potencial para promoção de saúde (Parada et al. 2008, Jácome et al. 2011). Dessa forma, nas localidades em que há um maior número de equipes Saúde da Família, o número de internações hospitalares por câncer de mama é menor, conforme observado na presente pesquisa, em que a associação entre essas duas variáveis foi negativa, com dependência espacial em nível global e local no período analisado.

\section{Conclusão}

Este estudo analisou os determinantes econômico e de gestão das internações hospitalares do SUS por câncer de mama entre as microrregiões brasileiras, no ano de 2013, utilizando-se da econometria espacial (Análise Exploratória de Dados Espaciais (AEDE), os modelos econométricos espaciais e o Geographically Weighted Regression).

De acordo com os resultados, verificou-se a existência de dependência espacial das internações hospitalares por câncer de mama entre as microrregiões brasileiras, sendo observadas aglomerações do tipo Alto-Alto no Sudeste e Centro-Sul e do tipo Baixo-Baixo no Norte e Nordeste do país. Observou-se associação positiva do PIB per capita, mamógrafos e número de consultas da Atenção Básica sobre as internações por essa doença. Por sua vez, a relação negativa ocorreu com o número de equipes de Saúde da Família. Destaca-se ainda a influência das regiões vizinhas na determinação dos condicionantes dessa morbidade.

Evidenciou-se, por um lado, que o PIB per capita, PIB per capita defasado, equipes de saúde, equipes de saúde defasadas e consultas de Atenção Básica defasadas espacialmente exerceram impacto local sobre o número de internações por neoplasia mamária em poucas microrregiões do Brasil. Já por outro, este efeito não foi significativo para diversas áreas analisadas, ou apresentaram efeitos contrários ao esperado, pelo modelo GWR.

Destaca-se que a distribuição espacial das internações hospitalares por câncer de mama entre as microrregiões pode refletir as inequidades no acesso aos serviços de saúde por todo o Brasil, incluindo a distribuição irregular de profissionais de saúde e dificuldade na realização de exames preventivos. Ademais, a alta rotatividade de profissionais de saúde, necessidade de qualificação e alta demanda de atendimento também podem estar se refletindo na distribuição espacial da variável analisada.

Portanto, a identificação das microrregiões do Brasil com maior número de internações hospitalares do SUS pela doença e seus principais determinantes espaciais possibilitam que políticas de saúde pública sejam direcionadas para essas áreas específicas. Além disso, ações mais ativas acerca da equidade no acesso aos serviços de saúde, no que diz respeito à melhor distribuição de médicos por todo o território nacional, qualificação profissional e equipes multiprofissionais que atuem sobre a promoção de hábitos saudáveis, conscientização dos sinais e sintomas da doença e da importância da prevenção, independentemente do nível socioeconômico, também são essenciais para a redução da ocorrência desta enfermidade. 


\section{Referências Bibliográficas}

Almeida, E. (2012), Econometria espacial, São Paulo: Alínea.

Almeida, E. S. D., Perobelli, F. S. \& Ferreira, P. G. C. (2008), 'Existe convergência espacial da produtividade agrícola no Brasil?', Revista de Economia e Sociologia Rural 46(1), 31-52.

Alvarez, P. L. L., Guerra-Yi, M. E., Faes, C., Alvarez, Y. G. \& Molenberghs, G. (2009), 'Spatial analysis of breast and cervical cancer incidence in small geographical areas in Cuba, 1999-2003', European Journal of Cancer Prevention 18(5), 395-403.

Anselin, L. (1988), Spatial econometrics: methods and models, Dordrecht: Kluwer.

Anselin, L. (1995), 'Local indicators of spatial association-LISA', Geographical analysis $27(2), 93-115$.

Anselin, L. (1999), 'Interactive techniques and exploratory spatial data analysis', Geographical Information Systems: principles, techniques, management and applications 1, 251-264.

Azevedo, S. G., Teixeira, M. T. B., Aquino, E. M. L., Tomazelli, J. G. \& SantosSilva, I. D. (2014), 'Acesso à detecção precoce do câncer de mama no Sistema Único de Saúde: uma análise a partir dos dados do Sistema de Informações em Saúde', Cad. Saúde Pública 30(7), 1537-1550.

Bello, M. A. (2010), 'Análise estatística espacial da mortalidade por câncer de mama feminina no estado do Rio de Janeiro, 2001 a 2006’.

Beysebayev, E., Bilyalova, Z., Kozhakeeva, L., Baissalbayeva, A. \& Abiltayeva, A. (2015), 'Spatial and temporal epidemiological assessment of breast cancer incidence and mortality in Kazakhstan, 1999-2013', Asian Pac. J. Cancer Prev 16(15), 6795-6798.

Boland, M. \& Murphy, J. (2012), 'The economic argument for the prevention of ill-health at population level'. $39 \mathrm{p}$.

Brasil (2007), Introdução à estatística espacial para a saúde pública, Brasília: Ministério da Saúde. Ministério da Saúde - Secretaria de Vigilância em Saúde.

Brasil (2010a), Câncer no Brasil: dados dos registros de base populacional, v.4, Rio de Janeiro: INCA. Disponível em: http://bvsms.saude.gov.br/bvs/publicacoes/inca/cancer_brasil_registro_po pulacional_completo.pdf.

Brasil (2010b), 'Entre o público e o privado'. Rede Câncer 11, 31-33, Rio de Janeiro: INCA, Disponível em: http://www.inca.gov.br/wps/wcm/connect/8e36ac004eb6935989189bf11fae00 ee/RC11_31_33politica.pdf?MOD=AJPERES.

Brasil (2011), Estimativa 2012: incidência de câncer no Brasil, Rio de Janeiro: INCA. Disponível em: http://portal.saude.sp.gov.br/resources/ses/perfil/gestor/homepage/estimati vas-de-incidencia-de-cancer-2012/estimativas_incidencia_cancer_2012.pdf. 
Brasil (2013), Controle dos Cânceres do Colo do Útero $e$ da Mama, Ministério da Saúde. Brasília: Ministério da Saúde. Secretaria de Atenção à Saúde, Disponível em: http://bvsms.saude.gov.br/bvs/publicacoes/controle_canceres_colo_utero_ 2013.pdf.

Brasil (2015), Estimativa 2016: incidência de câncer no Brasil, Rio de Janeiro: INCA. Disponível em: http://www.inca.gov.br/estimativa/2016/.

Brasil (2017a), 'Câncer de mama', Rio de Janeiro: INCA. Disponível em: http://www2.inca.gov.br/wps/wcm/connect/tiposdecancer/site/home/mama /cancer_mama+.

Brasil (2017b), 'Morbidade Hospitalar do SUS'. Disponível em: http://datasus.saude.gov.br.

Brasil (2018), 'CNES - estabelecimento por tipo'. Brasília: Ministério da Saúde. Disponível em: http://www2.datasus.gov.br/DATASUS/index.php?area=0204\&id=6906.

Brunsdon, C., Fotheringham, A. S. \& Charlton, M. E. (1996), 'Geographically weighted regression: a method for exploring spatial nonstationarity', Geographical analysis 28(4), 281-298.

Chasco, C. (2013), 'GeoDaSpace: a resource for teaching spatial regression models'.

Chien, L. C., Deshpande, A. D., Jeffe, D. B. \& Schootman, M. (2012), 'Influence of primary care physician availability and socioeconomic deprivation on breast cancer from 1988 to 2008: a spatio-temporal analysis', PloS one $7(4)$, e35737.

Cunningham, R., Shaw, C., Blakely, T., Atkinson, J. \& Sarfati, D. (2010), 'Ethnic and socioeconomic trends in breast cancer incidence in New Zealand', BMC cancer 10, 674 .

Dey, S., Soliman, A. S., Hablas, A., Seifeldein, I. A., Ismail, K., Ramadan, M. \& Harford, J. (2010), 'Urban-rural differences in breast cancer incidence in Egypt (1999-2006)', The Breast 19(5), 417-423.

Domingos, C. M., Carvalho, B. G., Fonseca, W. A. D., Cordoni Junior, L. \& Nicoletto, S. C. S. (2017), 'Distribuição do Profissional Médico na Macrorregião Norte do Paraná: Inequidade entre os Municípios de Diferentes Portes Populacionais', Revista Brasileira de Educação Médica 41(1), 117-125.

Fei, X., Wu, J., Kong, Z. \& Christakos, G. (2015), 'Urban-rural disparity of breast cancer and socioeconomic risk factors in China', PLoS One 10(2), e0117572.

Florax, R. J., Folmer, H. \& Rey, S. J. (2003), 'Specification searches in spatial econometrics: the relevance of Hendry's methodology', Regional Science and Urban Economics 33(5), 557-579.

Fotheringham, A. S., Brunsdon, C. \& Charlton, M. (2002), Geographically Weighted Regression: The Analysis of Spatially Varying Relationships, New York: Wiley. 
Fukuda, Y., Umezaki, M., Nakamura, K. \& Takano, T. (2005), 'Variations in societal characteristics of spatial disease clusters: examples of colon, lung and breast cancer in Japan', International Journal of Health Geographics $4(1), 16$.

Getis, A. (2009), Spatial Autocorrelation, in M. M. Fischer \& A. Getis, eds, 'Handbook of applied spatial analysis: software tools, methods and applications', New York: Springer.

Goldberg, M., Calderon-Margalit, R., Paltiel, O., Ahmad, W. A., Friedlander, Y., Harlap, S. \& Manor, O. (2015), 'Socioeconomic disparities in breast cancer incidence and survival among parous women: findings from a populationbased cohort, 1964-2008', BMC cancer 15(1), 921.

Goovaerts, P. (2006), 'Geostatistical analysis of disease data: visualization and propagation of spatial uncertainty in cancer mortality risk using Poisson kriging and p-field simulation', International Journal of Health Geographics 5(1), 7.

Greene, W. H. (2012), Econometric analysis, Upper Saddle River, NJ: Pearson.

Guerra, M. R., Silva, G. A., Nogueira, M. C., Leite, I. C. G., Oliveira, R. D. V. C. D., Cintra, J. R. D. \& Bustamante-Teixeira, M. T. (2015), 'Breast cancer survival and health iniquities', Cadernos de Saude Publica 31(8), 1673-1684.

Gutiérrez, R. (2013), 'Ações do Enfermeiro no rastreamento e Diagnóstico do Câncer de Mama no Brasil', Revista Brasileira de Cancerologia 59(3), 459-466.

Herrmann, C., Ess, S., Thürlimann, B., Probst-Hensch, N. \& Vounatsou, P. (2015), ' 40 years of progress in female cancer death risk: a Bayesian spatiotemporal mapping analysis in Switzerland', BMC cancer 15(1), 666.

Jácome, E. D. M., Silva, R. M. D., Gonçalves, M. L. C., Collares, P. M. C. \& Barbosa, I. L. (2011), 'Detecção do Câncer de Mama: conhecimento, atitude e prática dos Médicos e Enfermeiros da estratégia Saúde da Família de Mossoró, RN, Brasil', Revista Brasileira de Cancerologia 57(2), 189-198.

Kendall, P. R. W. (2010), Investing in prevention improving health and creating sustainability, British Columbia: Office of the Provincial Health Officer.

Larsen, S. B., Olsen, A., Lynch, J., Christensen, J., Overvad, K., Tjønneland, A. \& Dalton, S. O. (2011), 'Socioeconomic position and lifestyle in relation to breast cancer incidence among postmenopausal women: a prospective cohort study, Denmark, 1993-2006', Cancer epidemiology 35(5), 438-441.

Lesage, J. P. (1998), 'Spatial Econometrics'. Mimeo. Disponível em: http://www.spatial-econometrics.com/html/wbook.pdf.

Lima-Costa, M. F. \& Matos, D. L. (2007), 'Prevalência e fatores associados à realização da mamografia na faixa etária de 50-69 anos: um estudo baseado na Pesquisa Nacional por Amostra de Domicílios (2003)', Cadernos de Saúde Pública 23, 1665-1673. 
Madhu, B., Srinath, K. M., Rajendran, V., Devi, M. P., Ashok, N. C. \& Balasubramanian, S. (2016), 'Spatio-Temporal Pattern of Breast Cancer-Case Study of Southern Karnataka, India', Journal of clinical \& diagnostic research 10(4), LC20-LC24.

Mohaghegh, P., Yavari, P., Akbari, M. E., Abadi, A., Ahmadi, F. \& Shormeij, Z. (2015), 'Relationships between family levels of socioeconomic status and distribution of breast cancer risk factors', Iranian journal of cancer prevention 8(1), 53.

Müller, N. C. D. S. (2009), 'Mortalidade por câncer de mama e de colo de útero: análise temporal e espacial, município de São Paulo, 1996 a 2006'.

Nakaya, T. (2016), GWR4.09 User Manual GWR4 Windows Application for Geographically Weighted Regression Modelling, GWR. Geographically Weighted Regression.

National Institutes of Health (2007), 'Economic Costs of Cancer Health Disparities: Summary of Meeting Proceedings'.

Ocaña-Riola, R., Montaño-Remacha, C. \& Mayoral-Cortés, J. M. (2016), 'Geographical and temporal variations in female breast cancer mortality in the municipalities of Andalusia (Southern Spain)', International journal of environmental research and public health 13(11), E1162.

Oliveira, E. X. G. D., Melo, E. C. P., Pinheiro, R. S., Noronha, C. P. \& Carvalho, M. S. (2011), 'Acesso à assistência oncológica: mapeamento dos fluxos origem-destino das internações e dos atendimentos ambulatoriais. O caso do câncer de mama', Cadernos de Saúde Pública 27, 317-326.

Oliveira, E. X. G. D., Pinheiro, R. S., Melo, E. C. P. \& Carvalho, M. S. (2011), 'Condicionantes socioeconômicos e geográficos do acesso à mamografia no Brasil, 2003-2008', Ciencia E saúde coletiva 16, 3649-3664.

Palmer, J. R., Boggs, D. A., Wise, L. A., Adams-Campbell, L. L. \& Rosenberg, L. (2012), 'Individual and neighborhood socioeconomic status in relation to breast cancer incidence in African-American women', American journal of epidemiology 176(12), 1141-1146.

Parada, R., Assis, M., Silva, R. C. F., Abreu, M. F., Silva, M. A. F., Dias, M. B. K. \& Tomazelli, J. G. (2008), 'A política nacional de atenção oncológica e o papel da atenção básica na prevenção e controle do câncer', Revista de APS 11(2), 199.

Perinetti, A. (2015), 'Análisis espacial de factores socioeconómicos, de servicios de salud y de mortalidad por cáncer de mama, Argentina, 2009-2011', Fundação Oswaldo Cruz. Rio de Janeiro: Fundação Oswaldo Cruz. (Dissertação de Mestrado em Epidemiologia em Saúde Pública) 155p.

Rey, S. J. \& Montouri, B. D. (1999), 'US regional income convergence: a spatial econometric perspective', Regional studies 33(2), 143-156.

Rodrigues, F. B., Santos, J. J. P., Pinto, W. M. \& Brandão, C. S. (2012), 'O papel do enfermeiro na prevenção do câncer de mama em um município do sertão pernambucano: uma abordagem da prática profissional', Saúde Coletiva Debate 2(1), 73-86. 
Rodrigues, J. D., Cruz, M. S. \& Paixão, A. N. (2015), 'Uma análise da prevenção do câncer de mama no Brasil', Ciência E Saúde Coletiva 20, 3163-3176.

Santiago, F. S. (2012), 'Acesso aos exames periódicos de saúde entre as mulheres brasileiras acima de 24 anos', Revista Brasileira de Estudos Regionais e Urbanos 6(2), 48-65.

Santos, R. S., Zaponni, A. L. B. \& Melo, E. C. P. (2009), 'Análise espacial da mortalidade do câncer de mama e colo de útero no Brasil em 2004', Revista de Pesquisa: Cuidado é Fundamental 1(2), 210-216.

Santos, S. D. S., Melo, L. R., Koifman, R. J. \& Koifman, S. (2013), 'Breast cancer incidence and mortality in women under 50 years of age in Brazil', Cadernos de saúde publica 29(11), 2230-2240.

Scheffer, M. (2015), Demografia Médica no Brasil 2015, São Paulo: Faculdade de Medicina da USP, Conselho Regional de Medicina do Estado de São Paulo, Conselho Federal de Medicina, $284 \mathrm{p}$.

Schneider, I. J. C., Giehl, M. W. C., Boing, A. F. \& D’Orsi, E. (2014), 'Rastreamento mamográfico do câncer de mama no Sul do Brasil e fatores associados: estudo de base populacional', Cadernos de Saúde Pública 30, 1987-1997.

Silveira, R. P. \& Pinheiro, R. (2014), 'Entendendo a necessidade de médicos no interior da Amazônia-Brasil', Rev. bras. educ. méd. 38(4), 451-459.

Teixeira, M. D. S., Goldman, R. E., Gonçalves, V. C. S., Gutiérrez, M. G. R. D. \& Figueiredo, E. N. D. (2017), 'Primary care nurses' role in the control of breast cancer', Acta Paulista de Enfermagem 30(1), 1-7.

Vieira, V M Webster, T. F., Weinberg, J. M. \& Aschengrau, A. (2008), 'Spatialtemporal analysis of breast cancer in upper Cape Cod, Massachusetts', International Journal of Health Geographics 7(1), 46.

World Health Organization (2014), World Cancer Report 2014, Stewart, B W and Wild, C P and eds. Disponível em: http://publications.iarc.fr/NonSeries-Publications/World-Cancer-Reports/World-Cancer-Report-2014.

Wünsch Filho, V. \& Moncau, J. E. C. (2002), 'Mortalidade por câncer no brasil 1980-1995: padrões regionais e tendências temporais', Rev Assoc Med Bras 48(3), 250-257.

Xia, C., Kahn, C., Wang, J., Liao, Y., Chen, W. \& Yu, X. Q. (2016), 'Temporal trends in geographical variation in breast cancer mortality in China, 1973-2005: An analysis of nationwide surveys on cause of death', International journal of environmental research and public health 13(10), 963.

Zapponi, A. L. B. \& Melo, E. C. P. (2010), 'Distribuição da mortalidade por câncer de mama e de colo de útero segundo regiões brasileiras', Rev. enferm. UERJ 18(4), 628-631.

Zhou, H. B., Liu, S. Y., Lei, L., Chen, Z. W., Peng, J., Yang, Y. Z. \& Liu, X. L. (2015), 'Spatio-temporal analysis of female breast cancer incidence in Shenzhen, 2007-2012', Chinese journal of cancer 34(3), 13. 
